\title{
Chapter
}

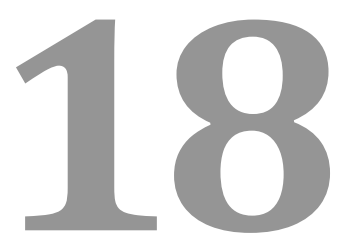

\section{GREEN NANOMATERIALS FOR PSORIATIC LESIONS}

Liliana Olenic ${ }^{1 *}$, Maria Crisan², Adriana Vulcu${ }^{1}$, Camelia Berghian-Grosan", Diana Crisan ${ }^{3}$, and Ioana Chiorean ${ }^{4}$

${ }^{1}$ National Institute for Research and Development of Isotopic and Molecular Technologies, 67-103 Donat Street RO 400293, Cluj-Napoca, Romania

${ }^{2}$ Histology Department, Iuliu Hatieganu University of Medicine and Pharmacy, 13 Emil Isaac Street, 400023 Cluj-Napoca, Romania ${ }^{3}$ Dermatology Clinic, Iuliu Hatieganu University of Medicine and Pharmacy, 13 Emil Isaac Street, 400023 Cluj-Napoca, Romania 4 Faculty of Mathematics and Informatics, Babes-Bolyai University, 1 Kogalniceanu Street, 400023 Cluj-Napoca, Romania 


\section{Contents}

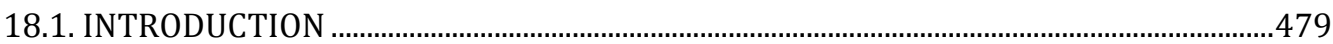

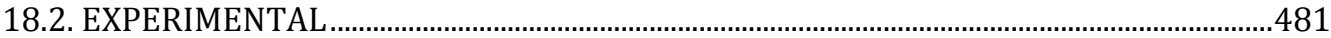

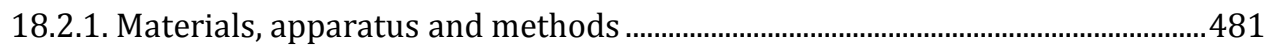

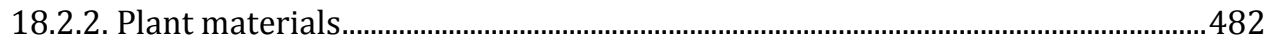

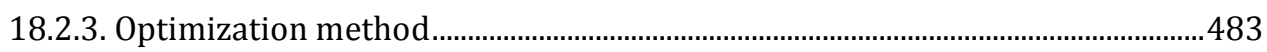

18.2.4. Synthesis of AuNPs / AgNPs-VO and AuNPs / AgNPs-K .....................................485

18.2.4.1. Calculation of metallic nanoparticle concentrations ............................485

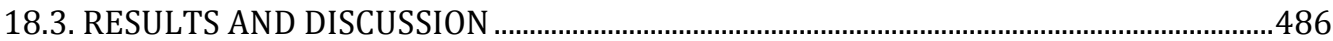

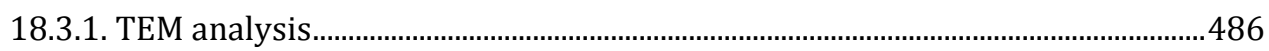

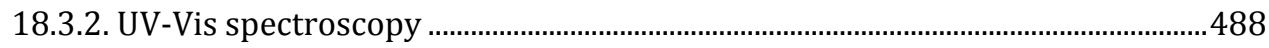

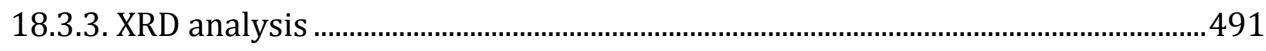

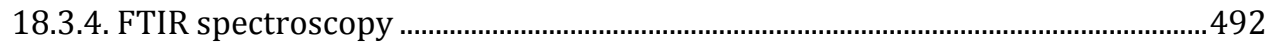

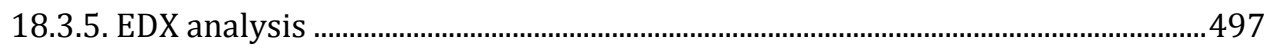

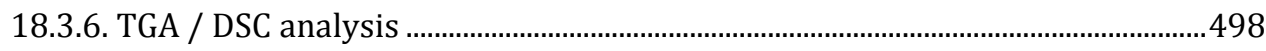

18.4. APPLICATION OF NANOMATERIALS ON PSORIATIC LESIONS.....................................501

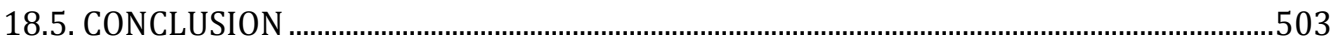

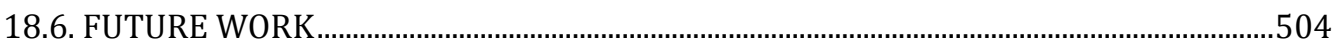

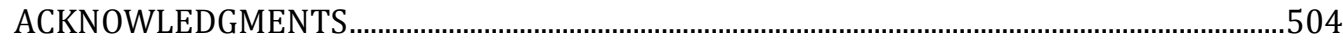

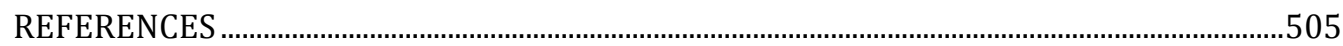




\subsection{INTRODUCTION}

Many diseases of the skin (e.g. psoriasis, dermatitis, eczema) are thought to be caused by infections, diet, and environmental factors, and in particular stress and anxiety. Psoriasis is a chronic inflammatory disease characterized by erythematous lesions with thick silvery scales on the surface, which are sometimes itchy [1]. Clinical medicine describes forms with fewer plagues, located on the elbows, knees or scalp; there are also generalized forms that affect large skin surfaces. Its prevalence in various populations is $1-3 \%$. The cause remains unknown but it has a strong genetic basis.

Mild forms receive a hygienic dietary regime and topical treatment. This type of treatment is long lasting, and must be adapted to the clinical form regarding the use of different ointments and creams. For the silver-white scaly forms, keratolytic or pickling substances are indicated and are included in ointments, such as salicylic acid, lactic acid (2-10\%) and urea (15-20\%). Also, topical treatment can include substances called tars which are obtained from petroleum distillation such as Ichthyol and Oleum Cadinum.

Other drugs are used that inhibit the proliferation of epidermal cells and regulate cell differentiation, including analogs of vitamin D3, i.e. calcipotriol and tacalcitol, found in creams and ointments. Topical corticosteroids provide a rapid and effective way to control localized psoriasis. For this reason, these compounds are frequently used by patients. However, ultra-high potency corticosteroids are not recommended for long-term therapy because there may be a rebound when they are discontinued and adverse effects such as atrophy and telangiectasia may occur. In general, topical treatment is indicated for patients with lesions that occupy less than $20 \%$ of the body.

Systemic treatment is reserved for skin lesions that affect more than $20 \%$ of the body surface and for severe forms of psoriasis (psoriatic erythoderma, psoriatic arthritis and pustular psoriasis). Biologicals are effective modern therapies that are targeted against psoriatic immune pathology and can induce long remission periods. In general, the treatment of psoriasis is prolonged and often combines topical and systemic therapy, based on the doctor's experience and patient compliance.

Although there are numerous therapies, psoriasis therapy has been and remains a challenge for researchers. In order to improve existing therapies or to discover new classes of drugs, there researchers have investigated the use of natural extracts and nanotechnology.

It is well-known that plants (roots, leaves and fruits) containing phenolic compounds have very good anti-inflammatory effects. Anthocyanins, the pigments that provide color to different plant tissues, are organic molecules that prevent the destructive action of free radicals in cells are thus very good 
antioxidants. The majority of biologically active components from plant extracts are poorly absorbed, so their action is very slow [2]. Due to their biological activities, these organic compounds are of interest in the food industry and in medicine [3-5]. For use in medicine, to potentiate the therapeutic role of these molecules, they could be attached as ligands to gold or silver nanoparticles. Both gold and silver colloids are non-allergenic. Furthermore, neither gold nor silver induce side effects. These metals have been intensively used in medicine for the treatment of different diseases (arthritis, infections, etc.). Nowadays, silver/gold colloid solutions are promoted as dietary supplements against different diseases. It has been found that colloidal metals formed in living organisms are assimilated faster than natural herbal remedies.

To be maintained in colloidal form, noble metals have to be surrounded by ligands with the same electrical charge. These nanomaterials with attractive new properties are synthesized directly or modified with chemical functional groups [6-8]. They are tailored to function in a desired application. In medicine, these particles are often conjugated with antibodies or drugs which permit their use as vehicles for drug delivery, diagnosis imaging or contrast agents [9-12].

To be used in medicine, metallic nanoparticles have to be non-toxic; as such, many studies have been performed on nanomaterials from a toxicological point of view. Most studies using these nanomaterials have been performed on different cell types in vitro. Even so, new nanomaterials are prepared and presented in the literature on a frequent basis. It is very important to verify if the new material is toxic or not, especially prior to use in medicine [13].

The metallic nanoparticles are prepared by many methods: chemical, physical and biological (bacteria, fungus, etc.) [14-21]. Some researchers have found that high concentrations of metallic nanoparticles are toxic to the human body. Release of these particles into the environment can cause ecological problems, as well. So, their use must have some limitations [22-24].

This is why the green approach is a very important way to prepare nanomaterials based on metallic nanoparticles using natural extracts from different parts of plants. Such methods, called "eco-friendly synthesis", allow us to obtain nanomaterials appropriate for use in medicine [25-42]. Studies on anthocyanins have been performed investigating their use as sensors for metallic ions [43], in surface-enhanced raman scattering (SERS) preparation [44], in clinical medicine [45-51], and as antioxidants [52,53], when bonded to different non-metallic nanoparticles [54]. Some studies have been performed using nanomaterials on porcine skin [55] or for applications such as clinical ultrasound gels and topical antimicrobial gels [56,57], for dermal fibroblast cells in humans [58], skin diseases [59] and in cosmetics [60]. To our knowledge, metallic nanoparticles bonded to anthocyanins as ligands have not 
been prepared and used in medicine, but are used in the energy industry to obtain dye-sensitized solar cells $[61,62]$.

The majority of papers that refer to the green synthesis of metallic nanoparticles use extracts from leaves or fruits at high temperatures, such that the anthocyanins are decomposed. In these cases, metallic nanoparticles are surrounded by organic molecules from plants other than anthocyanins.

Our team is involved in obtaining metallic nanoparticles conjugated with anthocyanins from fruit extracts from the Adoxaceae and Cornaceae families. Here, we present a part of our study and the use of an eco-friendly synthesis method which allowed us to obtain new nanomaterials based on gold / silver nanoparticles with anthocyanin molecules from fruit extracts of Viburnum opulus L. (VO), which contains the anthocyanin kuromanin chloride (K) as the ligand [63]. Comparatively, we have prepared, using the same method, nanomaterials with pure anthocyanin kuromanin chloride.

The prepared nanomaterials were characterized by ultraviolet-visible (UV-Vis) and Fourier transform infrared (FTIR) spectroscopy, transmission electron microscopy (TEM), X-ray diffraction (XRD), energy dispersive X-ray spectroscopy (EDX), thermogravimetric analysis (TGA) and differential scanning calorimetry (DSC) analysis. After the nanomaterials were analyzed from a toxicological point of view in vitro and in vivo [63-68], they were added to a cream base and used in medicine to treat psoriatic lesions. The results were statistically assessed.

\subsection{EXPERIMENTAL}

\subsubsection{Materials, apparatus and methods}

Chemicals (tetrachloroauric acid, silver nitrate, sodium hydroxide) used for the preparation of nanomaterials were of analytical grade, purchased from Merck, Germany. The pure anthocyanin (kuromanin chloride) was obtained from Sigma-Aldrich. Double distilled water was used for the preparation of solutions.

A JEOL-JEM 1010 (JEOL Inc.) instrument was used to assess the morphology and size distribution of the nanoparticles. The absorption spectra of synthesized nanoparticles were measured with a Shimadzu UV-Vis spectrometer (with a wavelength range between $300-850 \mathrm{~nm}$ at room temperature). The characterization of the molecular structures that formed between organic molecules and metallic nanoparticles was performed with a JASCO 6100 spectrometer (spectral domain $5000-500 \mathrm{~cm}^{-1}$; the resolution was $4 \mathrm{~cm}^{-1}$ with the sample as $\mathrm{KBr}$ pellets). The crystalline nature of nanoparticles was determined with a D8 Advance Diffractometer with $\mathrm{CuK} \alpha_{1}$ radiation $(\lambda=15.4056 \AA)$ and a Ge (111) monochromator. The elemental analysis (EDX) 
was performed with an Oxford Instruments with INCA Energy 300 software. TGA was performed using a SDT Q600 analyzer. The DSC experiments were carried out with a Shimadzu DSC-60 differential scanning calorimeter using Shimadzu TA-WS60 and TA60 2.1 version system software for data acquisition and analysis.

A non-invasive, high frequency ultrasound device Dermascan C $20 \mathrm{MHz}$ (Cortex Technology, Denmark) has been used for the assessment of psoriasis lesions.

\subsubsection{Plant materials}

The extracts from VO fruits (Adoxaceae family) (Figure 1) were obtained according to Moldovan et al. [69]. The total anthocyanin content from the crude extract was measured using a $\mathrm{pH}$ differential method [70,71]. For the reaction with metallic ions, the concentration of the anthocyanin solution was diluted to $25 \times 10^{-3} \mathrm{mM}$.

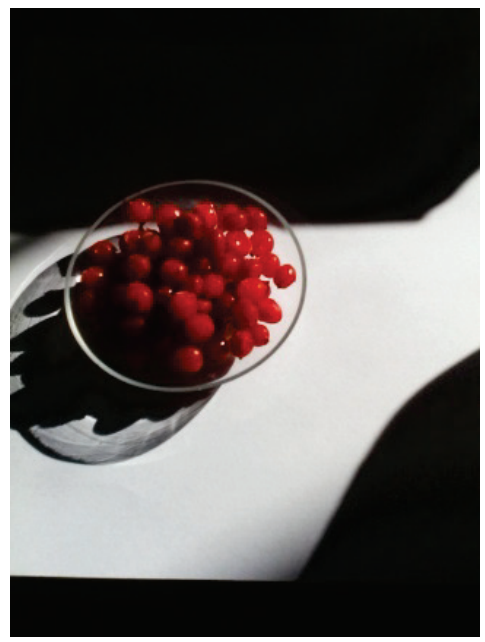

Figure 1. Picture of Viburnum opulus fruits

Some important factors in obtaining nanoparticles were closely followed $[63,72]$. The influence of the VO solution $\mathrm{pH}$ on the morphology of gold nanoparticles was studied. Anthocyanins in acidic solutions are found in cationic form (flavylium ions) but at neutral and basic solutions are found in the molecular form and anionic form, respectively (Figure 2). 

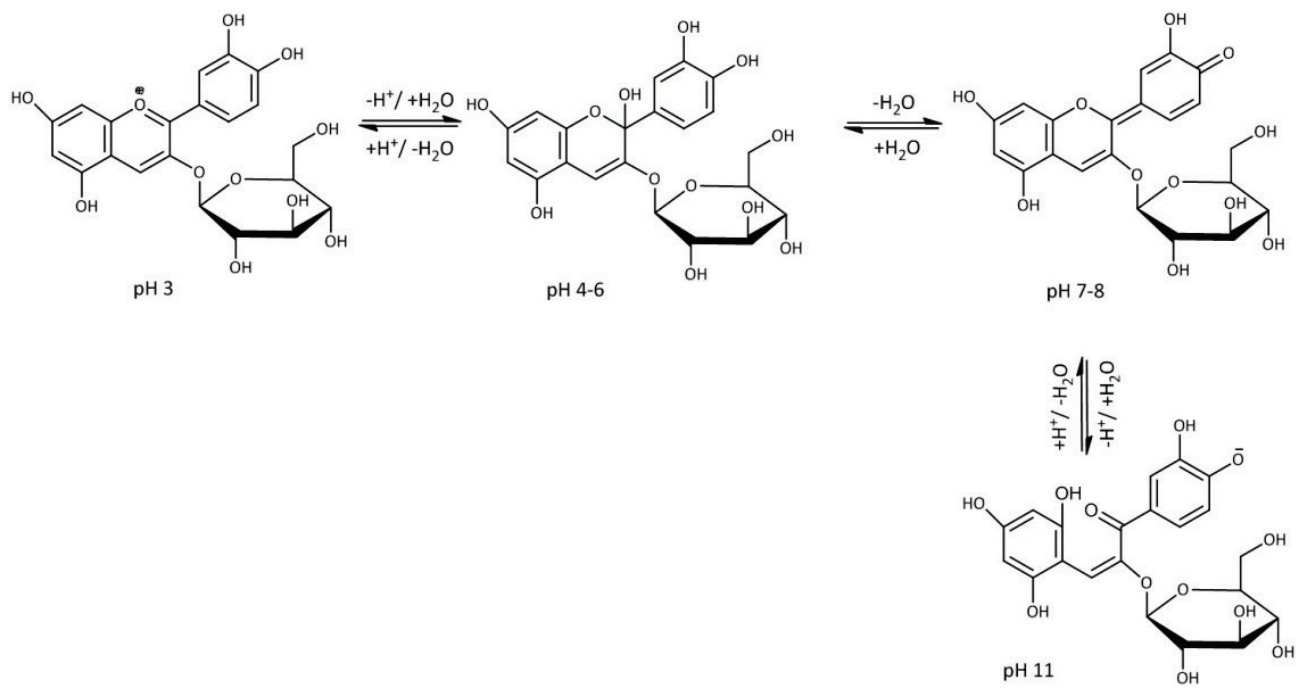

Figure 2. Different $\mathrm{pH}$ structures of the major anthocyanin from $\mathrm{VO}, \mathrm{K}$

\subsubsection{Optimization method}

Experiments were performed in acidic, neutral and basic VO solutions. Depending on the $\mathrm{pH}$ used, the final solutions had different shades of red or purple for gold and yellow or yellow-brown for silver. In Figure 3, TEM images of the nanomaterials at different $\mathrm{pH}$ levels are shown. At acidic $\mathrm{pH}$, the nanoparticles had diameters larger than $100 \mathrm{~nm}$, peaking at $200 \mathrm{~nm}$. At basic $\mathrm{pH}$, smaller round and triangular shaped nanoparticles were obtained. At $\mathrm{pH} \mathrm{7.5,} \mathrm{the} \mathrm{nanoparticle} \mathrm{size} \mathrm{was} \mathrm{spread} \mathrm{over} \mathrm{a} \mathrm{range} \mathrm{of} 12-90 \mathrm{~nm}$ and particles had round shapes. Although a high concentration of nanoparticles with a round shape was obtained at basic $\mathrm{pH}$, at this $\mathrm{pH}$, anthocyanin is present in chalcone form. Figure 4 shows the UV-Vis spectra of the nanomaterials. 


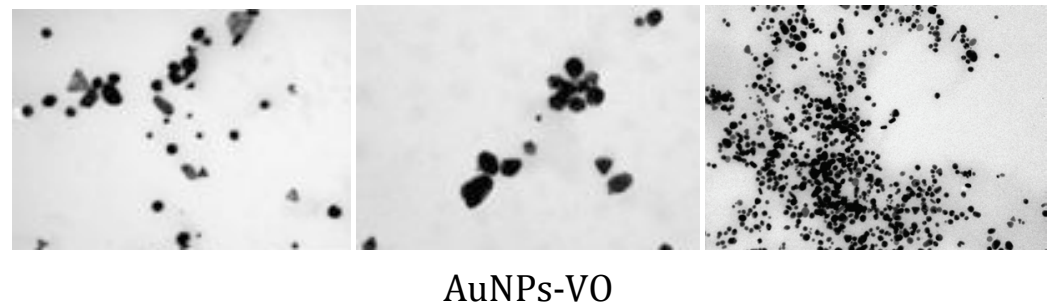

A: pH acid

B: pH neutral

$\mathrm{C}: \mathrm{pH}$ basic

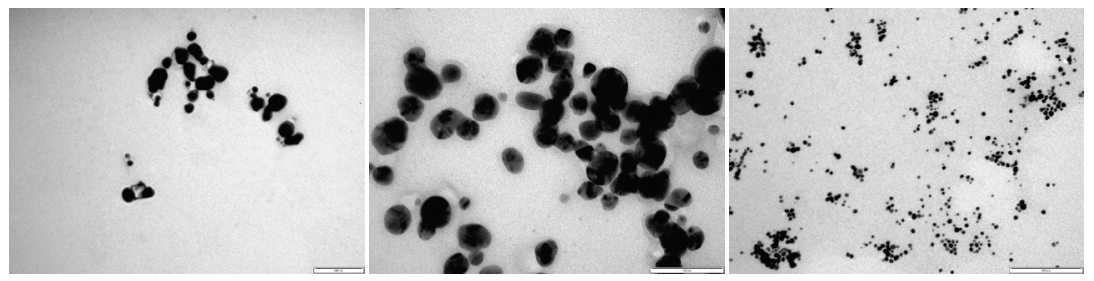

AgNPs-VO

D: $\mathrm{pH}$ acid

E: pH neutral

$\mathrm{F}: \mathrm{pH}$ basic

Figure 3. TEM images of AuNPs / AgNPs-VO at different $\mathrm{pH}$ levels (scale bar: AuNPs-VO: A-500 nm, B-100 nm, C-200 nm; AgNPs-VO: D-200 nm, $\mathrm{E}-100 \mathrm{~nm}, \mathrm{~F}-200 \mathrm{~nm}$ )
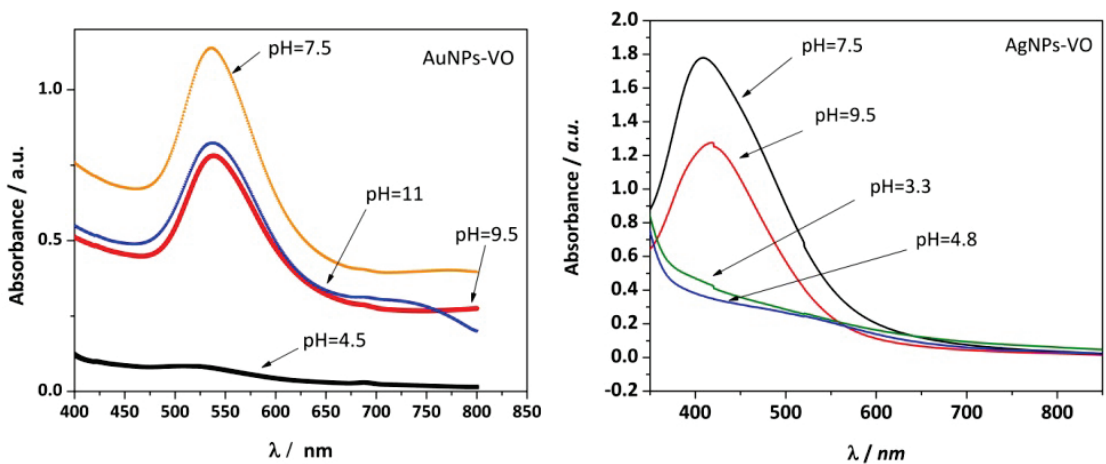

Figure 4. UV-Vis spectra of AuNPs / AgNPs-VO obtained at different pH levels

In order to obtain the best results in the reduction reaction, the ratio between the reactants, the temperature of the solution and the concentration of the solution were investigated.

When using pure anthocyanin, the concentration of the necessary solution for the reduction of gold ions was three times higher than when using extracts. It is likely that a greater concentration of pure anthocyanin for reduction is necessary in this case due to fact that there are other reductants in the extract (e.g. sugars). 


\subsubsection{Synthesis of AuNPs / AgNPs-VO and AuNPs / AgNPs-K}

The same method was used to prepare the nanomaterials with VO and $\mathrm{K}$ in view of the possibility of comparing the new products.

The procedure of Crisan et al. [63] was applied. The $\mathrm{pH}$ of VO and K solutions was adjusted to 7.5 with $1 \mathrm{M} \mathrm{NaOH}$. The concentration of the metallic ion solutions $\left(\mathrm{HAuCl}_{4}, \mathrm{AgNO}_{3}\right)$ was $1 \%$. In $200 \mathrm{~mL}$ of boiling distilled water, $6.6 \mathrm{~mL}$ of the silver ion solution and $16.6 \mathrm{~mL}$ of the $\mathrm{VO} / \mathrm{K}$ solution was added rapidly. In the case of gold ions, $6.6 \mathrm{~mL}$ of the metallic ion solution was added to $16.6 \mathrm{~mL}$ of VO solution or $50 \mathrm{~mL}$ of $\mathrm{K}$ solution. The solution was continuously stirred for $10 \mathrm{~min}$. Gold ion reduction took place after a few minutes in all cases; a red-purple color was obtained for $\mathrm{VO}$ and a red-mauve color for $\mathrm{K}$. The colors of the silver nanoparticle solution were yellow for $\mathrm{VO}$ and yellow-brown for $\mathrm{K}$. The colloids were stable for three weeks at $4{ }^{\circ} \mathrm{C}$. The nanomaterials were centrifuged twice at $15000 \mathrm{rpm}$ and $4{ }^{\circ} \mathrm{C}$ for $10 \mathrm{~min}$, then redissolved in double distilled water. For DSC, XRD and FTIR analyses, colloids were dried at room temperature on watch glasses.

\subsubsection{Calculation of metallic nanoparticle concentrations}

Based on the experimental results and according to the solution quantities and their concentrations used, the molar concentrations of metallic nanoparticle solutions were found to be $0.114 \mathrm{nM}$ for AuNPs-VO, $1.34 \mathrm{nM}$ for AgNPs-K, $0.033 \mathrm{nM}$ for AuNPs-K and $4.71 \mathrm{nM}$ for AgNPs-K (considering the mean particle diameter in the case of VO of $63 \mathrm{~nm}$ for gold and $35 \mathrm{~nm}$ for silver and in the case of $\mathrm{K} 95 \mathrm{~nm}$ for gold and $23 \mathrm{~nm}$ for silver). We found that the nanoparticles had a round form and similar dimensions. 


\subsection{RESULTS AND DISCUSSION}

\subsubsection{TEM analysis}

TEM is one of the most efficient and versatile methods for the characterization of nanomaterials. TEM analysis provides information about the size and size distribution, morphology and dispersion of nanoparticles $[73,74]$.

(a)
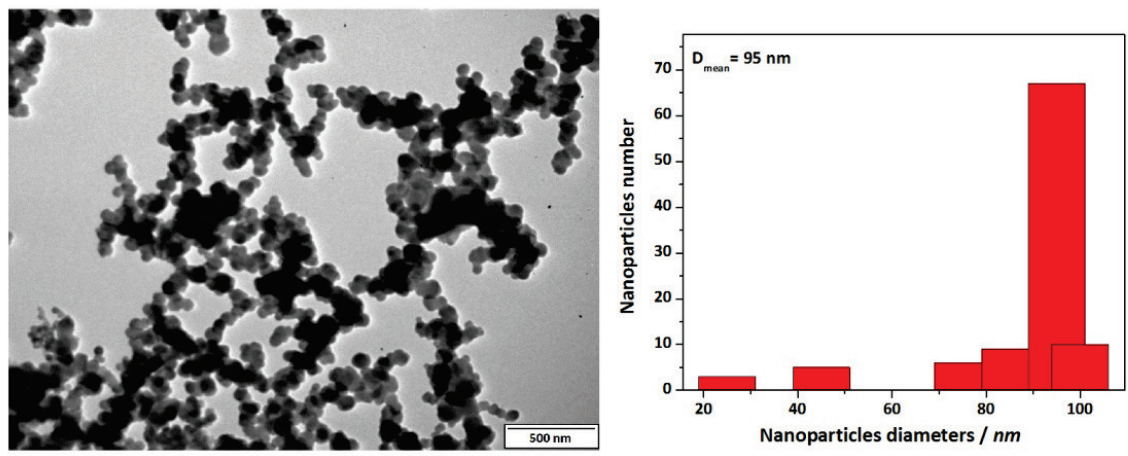

(b)
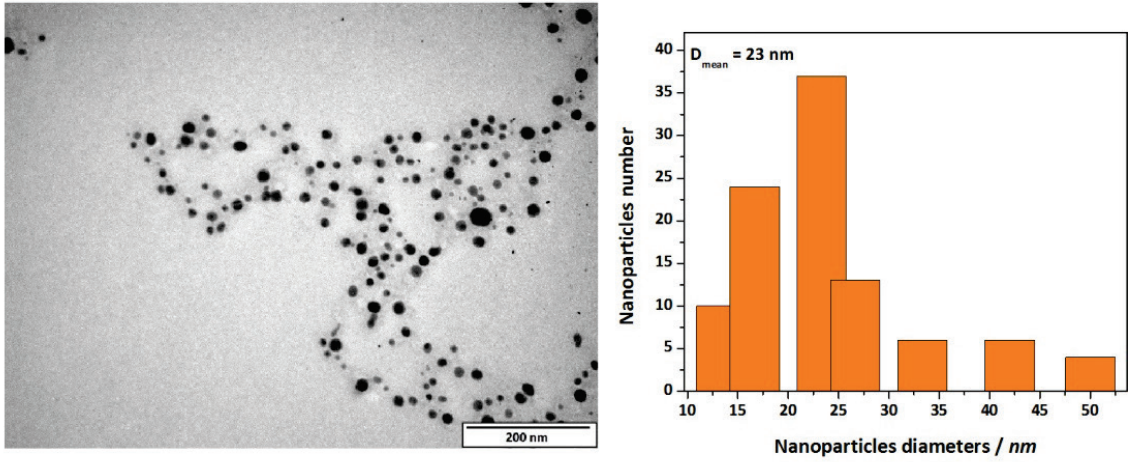

Figure 5. Representative TEM images of (a) AuNPs-K and (b) AgNPs-K and the associated particle size histograms

Figure 5 presents TEM images and the associated particle size histograms of AuNPs-K (a) and AgNPs-K (b). Examination of the TEM images of AuNPs-K (Figure 5a) revealed the formation of agglomerated nanoparticles (clusters) having a predominantly spherical shape. The size distribution of AuNPs-K was obtained by counting more than 100 nanoparticles; the mean diameter was found to be $95 \mathrm{~nm}$. The morphology of AgNPs-K (Figure 5b) highlights the formation of well-dispersed spherical nanoparticles. The particle size data 
were obtained from the associated histogram; the average diameter was found to be $23 \mathrm{~nm}$.

The nanomaterials based on gold / silver nanoparticles and natural extracts from VO were also characterized by TEM (Figure 6).

(a)
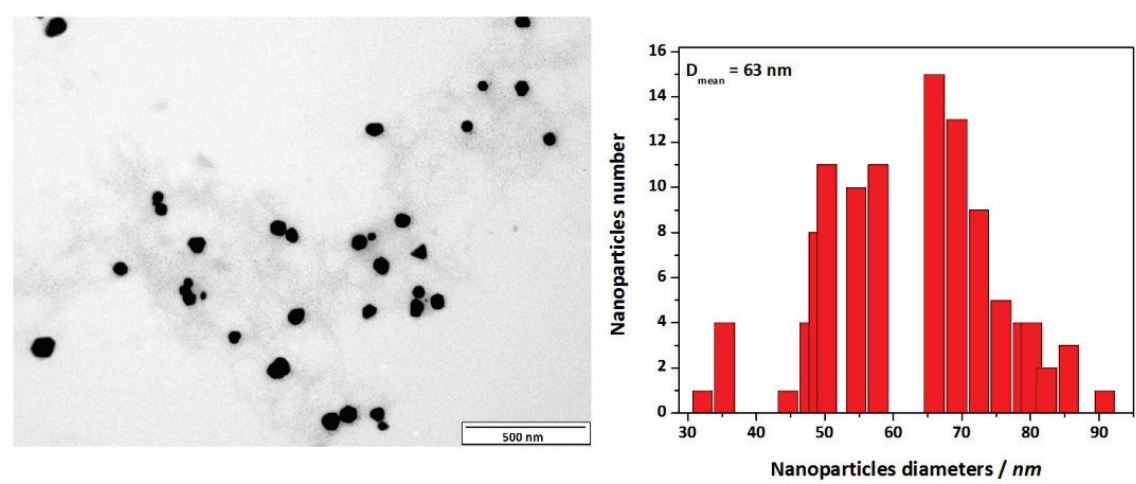

(b)
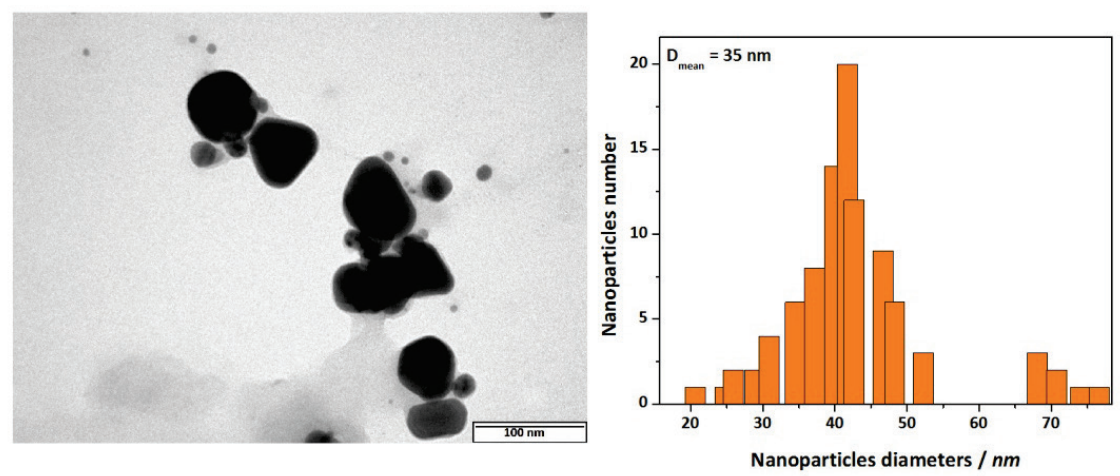

Figure 6. Representative TEM images of (a) AuNPs-VO and (b) AgNPs-VO and the associated particle size histograms

One can see the differences between the nanomaterials based on natural extracts (AuNPs-VO and AgNPs-VO) and nanomaterials based on pure anthocyanin (AuNPs-K and AgNPs-K) in terms of both size and shape. This can be explained considering the fact that the natural extract contains, besides anthocyanin, other compounds that have a reducing effect.

The TEM images of AuNPs-VO and AgNPs-VO (Figure 6) reveal the formation of well-dispersed nanoparticles with various shapes (spherical, tetrahedral and triangular). The nanoparticle diameters were obtained from the associated 
histograms and were found to be in the range of $30-90 \mathrm{~nm}$ for AuNPs-VO (Figure 6a) and 20-70 nm for AgNPs-VO (Figure 6b). The mean diameter obtained for AuNPs-VO was $63 \mathrm{~nm}$, which is smaller than that obtained for AuNPs-K. In the case of AgNPs-VO, the average diameter was 35 and was larger than that obtained for AgNPs-K.

\subsubsection{UV-Vis spectroscopy}

UV-Vis spectroscopy is a valuable tool for nanomaterial characterization and involves the absorption of near-UV or visible light. The optical properties of noble metal nanoparticles have been intensively studied. Metallic nanoparticles, in particular gold and silver nanoparticles, exhibit a strong absorption band in the visible region of the absorption spectra. This absorption band is a result of the coherent oscillation of conduction band free electrons induced by the interaction with the electromagnetic field of the incident light; this is known as surface plasmon resonance (SPR). This band is characteristic for metallic nanoparticles and is absent in the bulk metal absorption spectra. The position, intensity and shape of the SPR band depend on the size and shape of the particle, interparticle interactions, dielectric properties and the surrounding media. By varying the nanoparticle size and shape, the maximum absorbance of SPR can be tuned anywhere between 520-1000 nm [75-77].

Figure 7 presents the UV-Vis spectra of nanomaterials based on gold / silver and pure anthocyanin. A broad absorption peak was observed in the absorption spectra of AuNPs-K (Figure 7a) at $560 \mathrm{~nm}$, while for AgNPs-K (Figure $7 \mathrm{~b}$ ) the SPR band appeared at $410 \mathrm{~nm}$. 
(a)
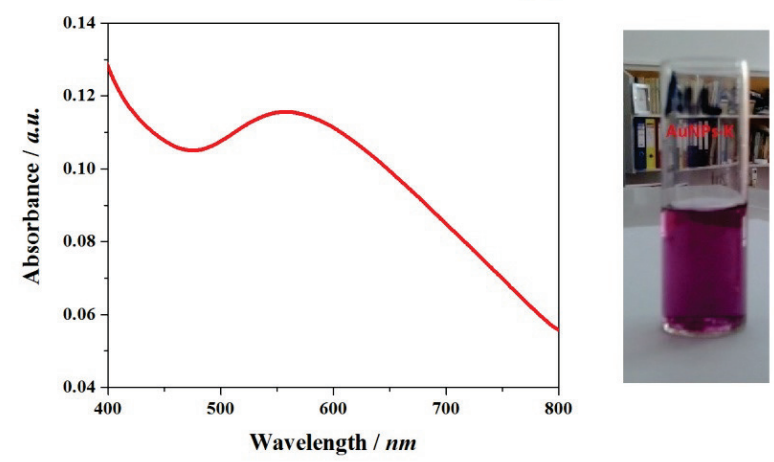

(b)
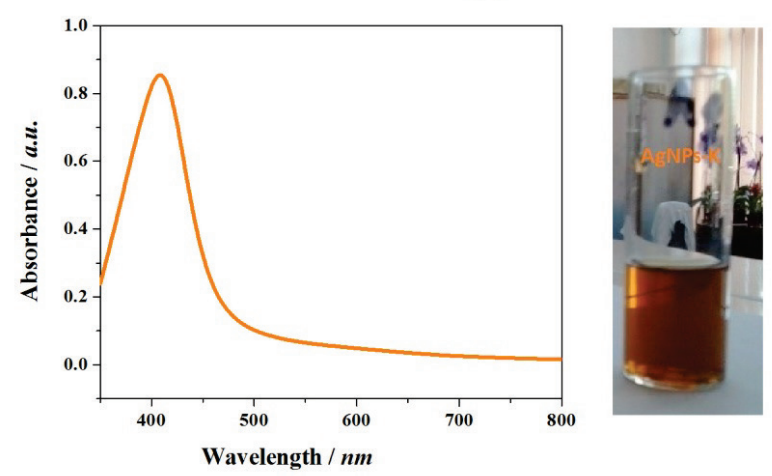

Figure 7. UV-Vis spectra of (a) AuNPs-K and (b) AgNPs-K (dilution $1: 2$ )

For nanomaterials based on natural extracts and gold / silver nanoparticles, the SPR band appeared at $545 \mathrm{~nm}$ for AuNPs-VO (Figure 8a) and 430 for AgNPs-VO (Figure 8b). One can see that, in the case of AuNPs-VO, the SPR band was narrower and shifted to lower wavelengths, indicating a decrease in nanoparticle size, while for AgNPs-VO, the SPR band underwent a small shift to higher wavelengths, indicating an increase in particle size. 
(a)
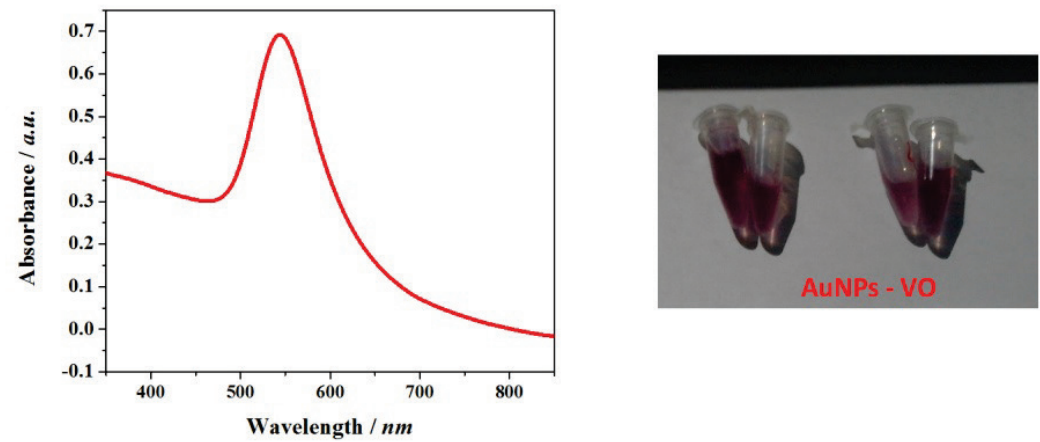

(b)
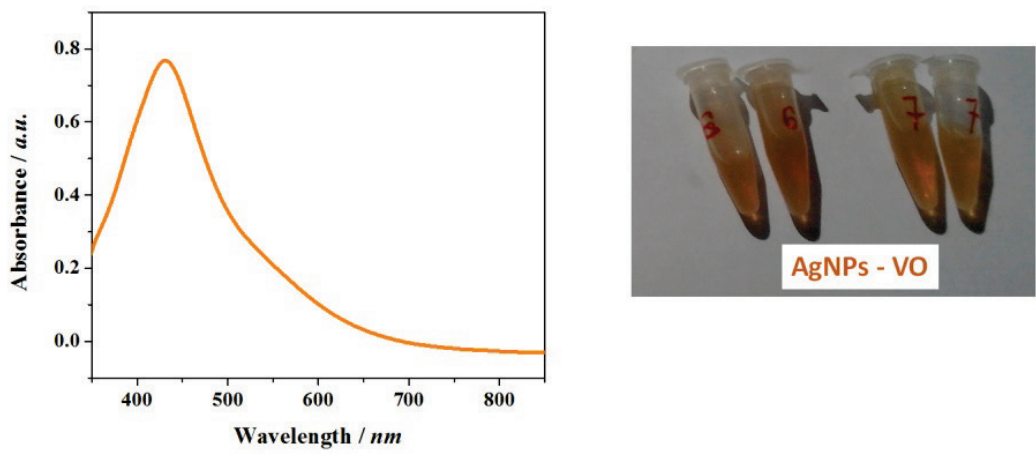

Figure 8. UV-Vis spectra of (a) AuNPs-VO and (b) AgNPs-VO (dilution $1: 2$ )

The results obtained from UV-Vis measurements were in concordance with the TEM images and confirmed the morphology of the nanomaterials. These results are presented comparatively in Table 1.

Table1. Comparison data between UV-Vis and TEM measurements

\begin{tabular}{lccc}
\hline & $\begin{array}{c}\text { SPR band position } \\
{[\mathrm{nm}]}\end{array}$ & $\begin{array}{c}\text { Nanoparticle mean } \\
\text { diameter } \\
{[\mathrm{nm}]}\end{array}$ & $\begin{array}{c}\text { Absorbance } \\
\text { [a.u.] }\end{array}$ \\
\hline AuNPs-K & 560 & 95 & 0.12 \\
\hline AuNPs-VO & 545 & 63 & 0.70 \\
\hline AgNPs-K & 410 & 23 & 0.85 \\
\hline AgNPs-VO & 430 & 35 & 0.80 \\
\hline
\end{tabular}




\subsubsection{XRD analysis}

The experimental XRD patterns of the nanomaterials based on gold / silver nanoparticles and pure anthocyanin (AuNPs-K and AgNPs-K) are presented in Figure 9. In the case of AuNPs-K, characteristic diffraction peaks were observed and assigned to the (111), (200), (220) and (311) planes of the face centered cubic (FCC) lattice of metallic gold. In the XRD pattern of AgNPs-K, only three diffraction peaks were observed, corresponding to the (111), (200) and (311) planes. The most intense peak was assigned to the (111) plane, suggesting that AgNPs-K have a predominantly crystalline structure.
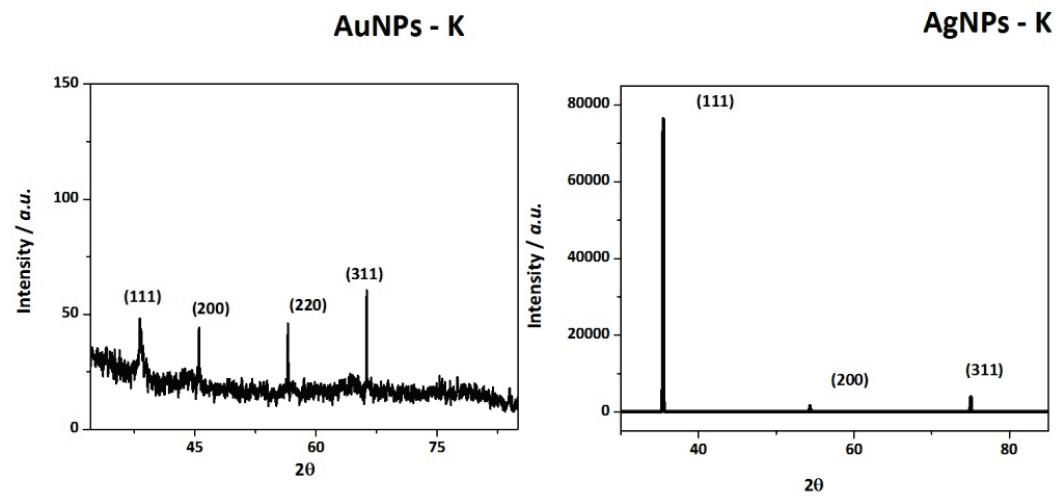

Figure 9. XRD patterns of the synthesized nanomaterials: AuNPs-K and AgNPs-K

The powder diffraction spectra of the nanomaterials synthesized using natural extracts and gold/silver nanoparticles showed five peaks located at $2 \theta: 38.14^{\circ}, 44.31^{\circ}, 64.56^{\circ}, 77.64^{\circ}$ and $81.85^{\circ}$ corresponding to the (111), (200), (220), (311) and (222) planes (Figure 10). The dominant peak corresponded to the (111) plane, suggesting that both AuNPs-VO and AgNPs-VO are crystalline in nature.
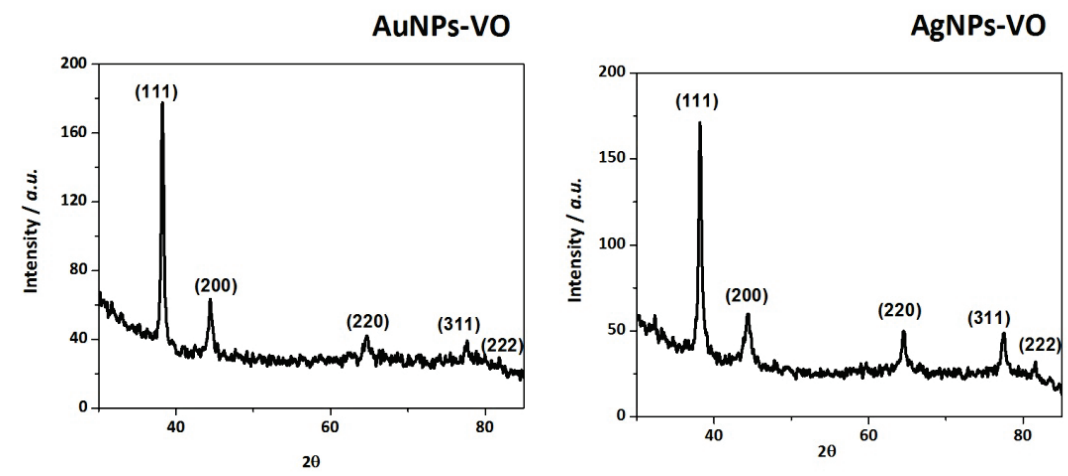

Figure 10. XRD patterns of synthesized nanomaterials: AuNPs-VO and AgNPs-VO 
The size of the synthesized nanomaterials was calculated using the Debye-Scherrer Equation (1):

$$
D=\frac{k \lambda}{\beta_{\mathrm{s}} \cos \theta}
$$

where $D$ is the nanomaterial's diameter, $k$ is the Scherrer constant, $\lambda$ is the wavelength of radiation, $\beta_{\mathrm{s}}$ is the full peak width and $\theta$ is the diffraction angle $[78,79]$. The Scherrer constant is approximately equal to unity (the most cited value in the literature for $k$ is 0.9 ) and is related to the crystalline shape $[80,81]$. Therefore, the following diameters were estimated for the crystallites: $D_{\text {AuNPs-K }}=30.2 \mathrm{~nm}, D_{\text {AgNPs-K }}=7.7 \mathrm{~nm}, D_{\text {AuNPs-vo }}=25 \mathrm{~nm}$ and $D_{\text {AgNPs-Vo }}=24 \mathrm{~nm}$. Due to the fact that one nanoparticle may contain multiple crystallites, the diameters obtained by XRD are smaller than those obtained by TEM analysis.

\subsubsection{FTIR spectroscopy}

Vibrational spectroscopy is a useful technique for nanomaterial characterization [82,83]. Both FTIR and Raman spectra can provide information on nanomaterial composition, but some disadvantages are encountered. For FTIR experiments, the complexity of the spectrum is regarded as a problem when working with a complex mixture, while for the Raman studies, fluorescence interference poses important challenges. Nevertheless, FTIR and Raman spectroscopy can be considered for chemical nanoparticle surface characterization $[84,85]$.

In the present chapter, we used FTIR spectroscopy for the identification of molecules linked to the surface of gold and silver nanoparticles. The FTIR spectra of kuromanin chloride (cyanidin-3-glucoside) and gold nanoparticles functionalized with kuromanin chloride (AuNPs-K) are shown in Figure 11. Second derivative spectra were also employed for the separation of overlapping signals. 


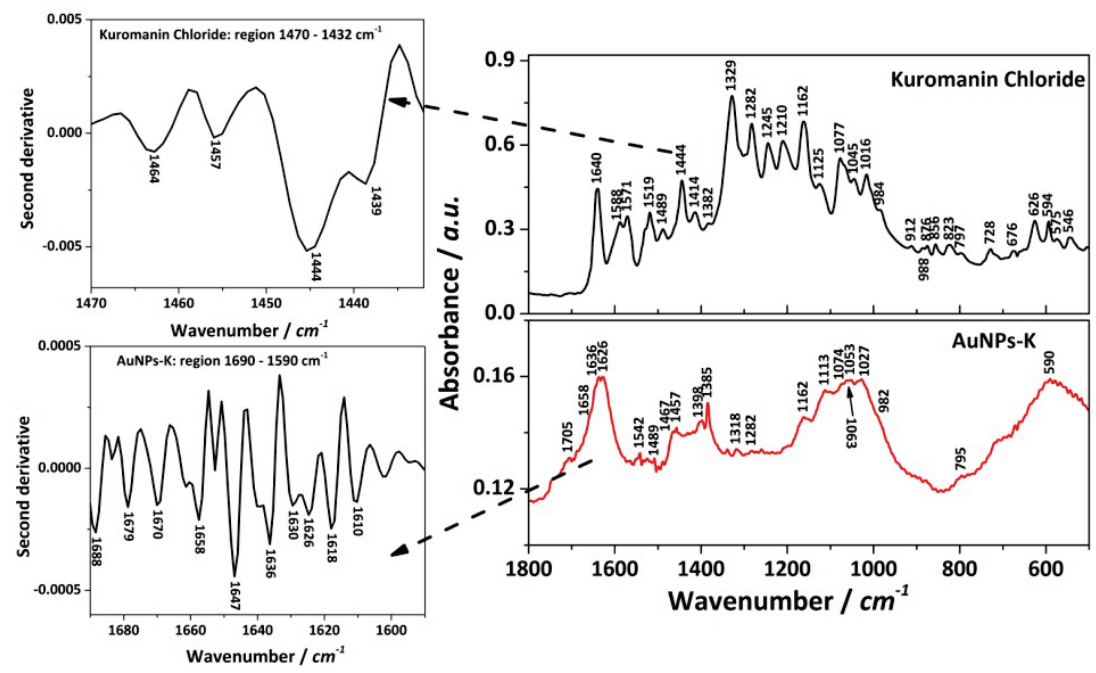

Figure 11. Solid FTIR spectra of $\mathrm{K}$ and gold nanoparticles functionalized with $\mathrm{K}$ (AuNPs-K) in the region $1800-500 \mathrm{~cm}^{-1}$; second derivative spectra of $\mathrm{K}$ in the region $1470-1432 \mathrm{~cm}^{-1}$ and AuNPs-K in the region $1690-1590 \mathrm{~cm}^{-1}$

In $\mathrm{K}$, the peak centered at $1640 \mathrm{~cm}^{-1}$ could be related to the stretching vibrations of the aromatic $\mathrm{C}=\mathrm{C}$ from anthocyanin $(v \mathrm{C}=\mathrm{C})$; the bending vibration of water (from the $\mathrm{KBr}$ pellet or the water from $\mathrm{K}$ ) can also appear in this region [86,87]. In AuNPs-K, the band at $1640 \mathrm{~cm}^{-1}$ broadens and new vibrations appear at about 1705, 1658, 1647, 1636, 1626 and $1618 \mathrm{~cm}^{-1}$, indicating the formation of $\mathrm{C}=0$ bonds and a change in ring in-plane vibrations from the benzopyrylium unit when anthocyanin is linked to the gold surface (Figure 11; AuNPs-K and AuNPs-K second derivative spectrum) [88]. The FTIR bands located at 1588,1571,1519, 1489, 1444 and $1414 \mathrm{~cm}^{-1}$ in $\mathrm{K}$ can be ascribed to aromatic ring vibrations [86,88]; these bands disappear in AuNPs$\mathrm{K}$, which is consistent with the changes discussed above. The band observed at $1457 \mathrm{~cm}^{-1}$ could be from the $\beta$-glucopyranose moiety $(\mathrm{O}-\mathrm{C}-\mathrm{H}$ and $\mathrm{C}-\mathrm{C}-\mathrm{H}$ bending vibrations) [89]. This band is clearly seen in AuNPs-K (Figure 11) and it is masked in $\mathrm{K}$ (Figure 11; $\mathrm{K}$ second derivative spectrum). Its presence in the AuNPs-K spectrum indicates the existence of a sugar moiety in anthocyanin linked to the gold nanoparticle surface.

The 1400-1200 $\mathrm{cm}^{-1}$ region in the anthocyanin spectrum was strongly affected by interaction with the gold surface. The band located at $1329 \mathrm{~cm}^{-1}$ may be attributed to inter-ring stretching vibrations and could be used as a marker of the change in aromaticity and $\pi$-electron delocalization within the rings $[86,90]$. The other vibrations appearing in this region are mainly due to inplane $\mathrm{O}-\mathrm{H}$ bending mode, $\delta \mathrm{O}-\mathrm{H}$ coupled with $\mathrm{C}-\mathrm{OH}$ stretching vibrations from phenols, $v \mathrm{C}-\mathrm{O}$, and also to asymmetric $\mathrm{C}-\mathrm{O}-\mathrm{C}$ stretching vibrations from ethers, $v_{\text {as }} \mathrm{C}-\mathrm{O}-\mathrm{C}$ [86-88]. These bands disappear in the spectrum of anthocyanin coated gold nanoparticles. However, in AuNPs-K, new vibrations 
were seen in the $1411-1360 \mathrm{~cm}^{-1}$ domain; some of these vibrations could be associated with the frequencies from $1705-1610 \mathrm{~cm}^{-1}$ and could indicate a $\mathrm{C}=\mathrm{O}$ / gold interaction. This situation is similar to that observed for metallic chelates of conjugated ketones: when the $\mathrm{C}=0$ group is weakened by resonance between $\mathrm{C}-\mathrm{O}-\mathrm{M}$ and $\mathrm{C}=\mathrm{O}-\mathrm{M}$, the frequencies appear in the $1620-1610 \mathrm{~cm}^{-1}$ and $1390-1309 \mathrm{~cm}^{-1}$ ranges [91].

In the $1200-1000 \mathrm{~cm}^{-1}$ region, related to $\mathrm{C}-0$ stretching vibrations from pyranose coupled with $\mathrm{C}-\mathrm{C}$ stretching and symmetric $\mathrm{C}-\mathrm{O}$ stretching from ethers, some changes were observed. The difference between the two spectra was probably due to the transformation that occurred in the $\beta$-pyranose conformation after linking anthocyanin to gold nanoparticles and also to the disappearance of symmetric $\mathrm{C}-\mathrm{O}-\mathrm{C}$ stretching vibrations of aromatic ethers.

The band at $982 \mathrm{~cm}^{-1}$, ascribed to symmetric ring vibrations of $\beta$-pyranose, also reveals the existence of a $\beta$-pyranose moiety on the surface of gold nanoparticles in the AuNPs-K spectrum [88].

Taken together, the comparison of the two FTIR spectra, kuromanin chloride and AuNPs-K, indicates that the anthocyanin was bound to the surface of the gold nanoparticles. Significant changes related to $\pi$-delocalization between the benzopyrylium and phenol moieties were observed after the interaction of anthocyanin with gold nanoparticles.

European cranberry bush (VO) berries contain chlorogenic acid, cathechin, epicatechin, cyanidin-3-glucoside, cyanidin-3-rutinoside and different glucosides of quercetin [92]. According to Velioglu, between the two anthocyanin pigments, cyanidin-3-glucoside (kuromanin) is dominant in VO juice. In the FTIR spectrum of VO, the kuromanin seems to adopt the quinonoidal conformation under our experimental conditions, i.e. $\mathrm{pH} 7.5$. Thus, the band located at $1732 \mathrm{~cm}^{-1}$ could be the result of $\mathrm{C}=0$ stretching, and the absence of this band (Figure 12) may be associated with the aromaticity of kuromanin chloride (see the above discussion and Figure 11).

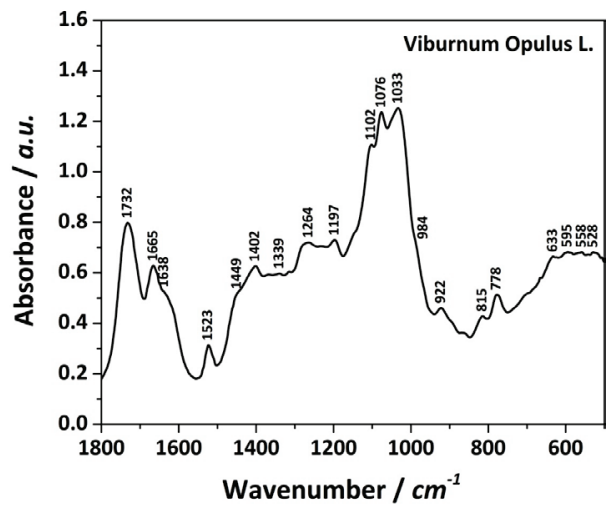

Figure 12. Solid FTIR spectra of VO extract in the $1800-500 \mathrm{~cm}^{-1}$ region 
In the $1200-1000 \mathrm{~cm}^{-1}$ region, the vibrations can be assigned to $\mathrm{C}-0$ stretching from pyranose coupled with $\mathrm{C}-\mathrm{C}$ stretching and symmetric $\mathrm{C}-\mathrm{O}$ stretching from ethers. The hydroxybenzoic acid, epicatechin and quercetin derivatives also possess strong vibrations in this spectral domain [93]. The band at $984 \mathrm{~cm}^{-1}$, ascribed to symmetric ring vibrations of $\beta$-pyranose, reveals the existence of a $\beta$-pyranose moiety in the VO spectrum [88].

In Figure 13, the solid FTIR spectra of gold nanoparticles obtained using kuromanin chloride (AuNPs-K) or VO extract solution (AuNPs-VO) are presented. For better comparison, the difference spectrum between AuNPs-VO and AuNPs-K is also shown.

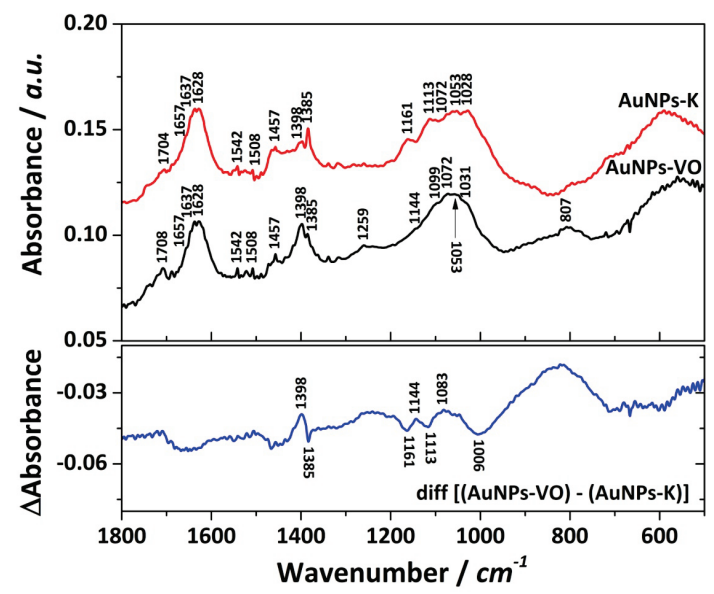

Figure 13. Solid FTIR spectra of gold nanoparticles obtained using kuromanin chloride (AuNPs-K) or VO extract (AuNPs-VO) and their difference spectrum in the $1800-500 \mathrm{~cm}^{-1}$ region

As shown in Figure 13, only few differences in the vibrational features of the two types of gold nanoparticles could be detected: an increase in the intensity of the peaks from 1398 and $1144 \mathrm{~cm}^{-1}$ and a reduction in the intensity of the frequencies located at 1385, 1161 and $1113 \mathrm{~cm}^{-1}$ when VO was used for gold nanoparticle synthesis.

The FTIR spectrum of silver nanoparticles obtained with kuromanin chloride (AgNPs-K) reveals almost the same bands as AuNPs-K; some differences seem to appear in the region 1711-1611 $\mathrm{cm}^{-1}$ and $1470-1450 \mathrm{~cm}^{-1}$ (Figures 11 and 14). 


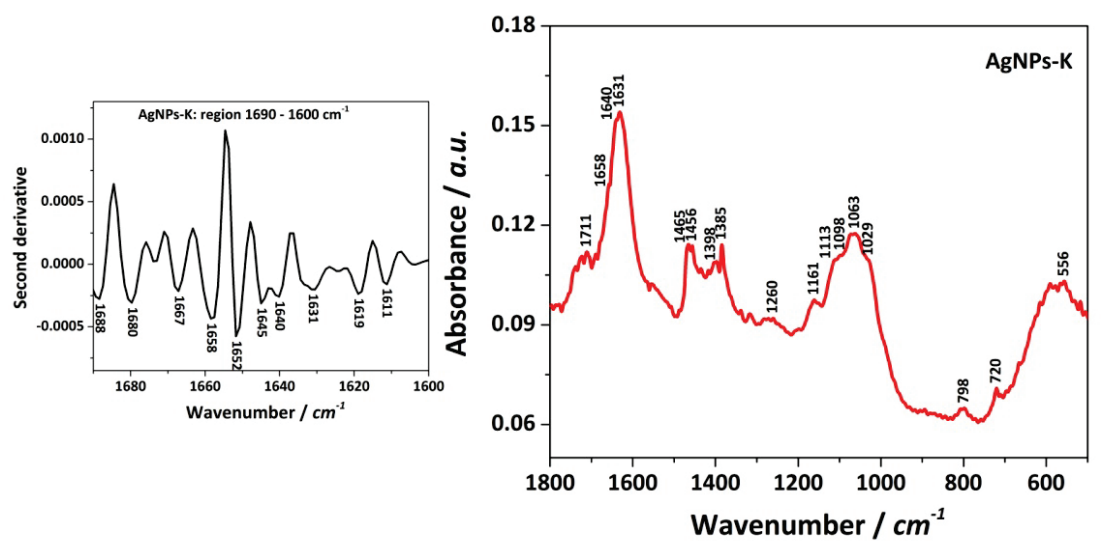

Figure 14. Solid FTIR spectra of silver nanoparticles functionalized with kuromanin chloride (AgNPs-K) in the $1800-500 \mathrm{~cm}^{-1}$ region and second derivative spectrum in the $1690-1600 \mathrm{~cm}^{-1}$ region

The presence of anthocyanin on the surface of silver nanoparticles could also be seen when the VO extract was used for the synthesis of silver nanoparticles (Figure 15). The difference spectrum between the two types of silver nanoparticles, diff [(AgNPs-VO)-(AgNPs-K)], highlights a decrease in band intensities from 1631 and $1465 \mathrm{~cm}^{-1}$ and a significant increase in the intensity of the peak at $1385 \mathrm{~cm}^{-1}$ when VO was used as the reducing agent.

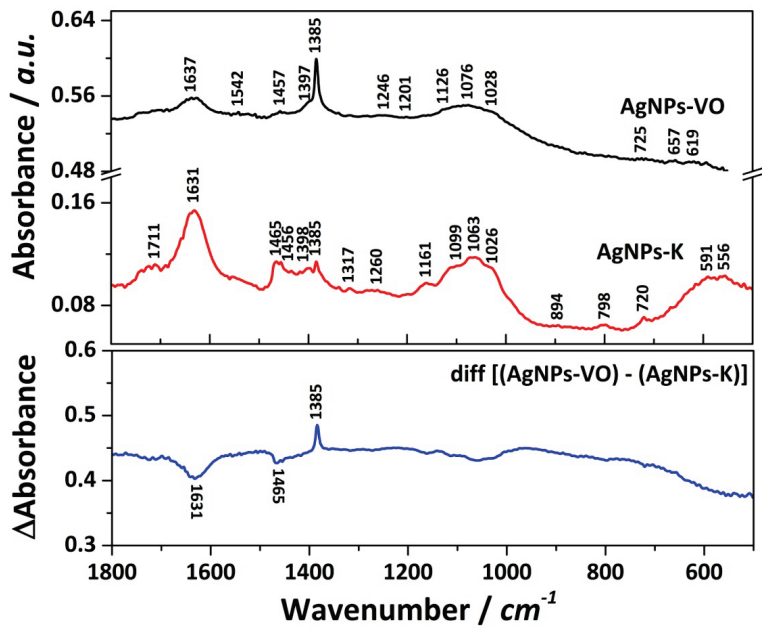

Figure 15. Solid FTIR spectra of silver nanoparticles obtained using kuromanin chloride (AgNPs-K) or VO extract (AgNPs-VO) and their difference spectrum in the $1800-500 \mathrm{~cm}^{-1}$ region 
In conclusion, anthocyanin is the major ligand bound to the surface of gold or silver nanoparticles, regardless of the protocol (with kuromanin chloride or VO extract) used for the synthesis of functionalized metallic nanoparticles.

\subsubsection{EDX analysis}

The analysis confirmed the presence of $\mathrm{Au}^{0} / \mathrm{Ag}^{0}$ in the samples by the appearance of a large peak for metals. Weak peaks for oxygen and carbon also confirmed the binding of organic molecules to the surface of gold/silver nanoparticles, as can be seen in Figure 16. In each case, three samples were analyzed and the mean for AuNPs-VO was found: approximately $89.52 \%$ gold, $4.76 \%$ oxygen and $7.30 \%$ carbon. In the case of AgNPs, the results were found to be: $80.76 \%$ silver, $3.62 \%$ oxygen and $5.39 \%$ carbon.
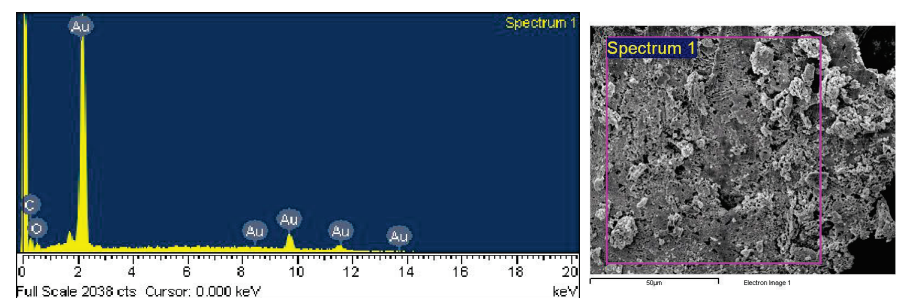

\begin{tabular}{|c|c|c|}
\hline Element & Weight $\%$ & Atomic $\%$ \\
\hline C K & 8.96 & 53.62 \\
\hline O K & 3.19 & 14.32 \\
\hline AuM & 87.85 & 32.00 \\
\hline Totals & 100.00 & \\
\hline
\end{tabular}

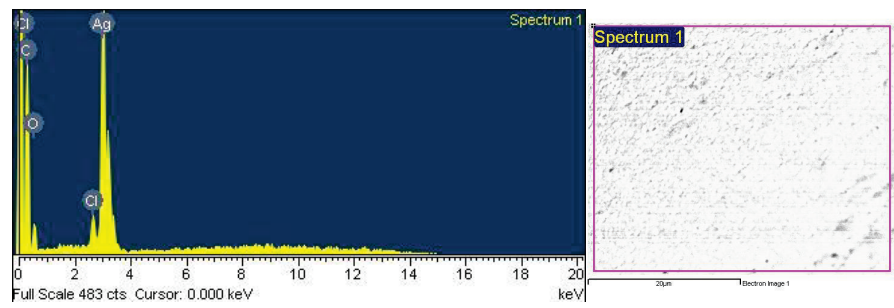

\begin{tabular}{|c|c|c|}
\hline Element & Weight \% & Atomic \% \\
\hline C K & 28.87 & 63.75 \\
\hline O K & 12.68 & 21.02 \\
\hline Cl K & 1.73 & 1.29 \\
\hline AgM & 56.72 & 13.94 \\
\hline Totals & 100.00 & \\
\hline
\end{tabular}

Figure 16. EDX spectra and field-emission scanning electron micrograph (FESEM) of AuNPs / AgNPs-VO 
Analyses indicated that the ligand involved in the formation of these nanomaterials contained only carbon and oxygen.

\subsubsection{TGA / DSC analysis}

It is known that the decomposition of anthocyanins is temperature sensitive. The decomposition of kuromanin chloride was assessed by Wang et al. [94], and they concluded that it takes place in three stages between $30-390{ }^{\circ} \mathrm{C}$. In the first stage, glucose is cleaved from the anthocyanin to produce cyanidin. In the second stage, the amount of anthocyanin is decreased to $13 \%$. Between $300-390{ }^{\circ} \mathrm{C}$, anthocyanin is degraded completely, and a large mass loss appears after heating to $390^{\circ} \mathrm{C}$. In the third stage, the mass loss of $37 \%$ corresponds to the decomposition of sugar.

In our case, in the TGA profile (Figure 17), one can see the decomposition temperature of AuNPs / AgNPs-VO at higher values $\left(800^{\circ} \mathrm{C}\right)$. This indicates the stability of organic molecules when they are bound to the gold surface. In the case of AuNPs-VO, the decomposition of organic molecules from the surface of the metal also took place in three stages between $110-450{ }^{\circ} \mathrm{C}, 450-800{ }^{\circ} \mathrm{C}$ and $800-900^{\circ} \mathrm{C}$. For AgNPs-VO, decomposition occurred in two stages between $200-450{ }^{\circ} \mathrm{C}$ and $450-810^{\circ} \mathrm{C}$. The shift in the decomposition temperature towards higher values also occurred in the case of amino acid capped gold nanoparticles [95].

The mass percent of organic molecules bound to gold clusters was approximately $9.93 \%$ (we assume that the first step weight loss of $0.6746 \%$ represents the desorption of water). Thus, $89.40 \%$ of the gold remained, which is comparable with the EDX results for AuNPs-VO, i.e. 89.52\%. In the case of AgNPs-V0, the percent desorption of water was $1.033 \%$ and the mass percent of organic molecules bound to silver nanoparticles was approximately $23.7 \%$. The remaining mass percent of silver was $75.27 \%$, comparable with the results obtained by EDX, i.e. $80.76 \%$.
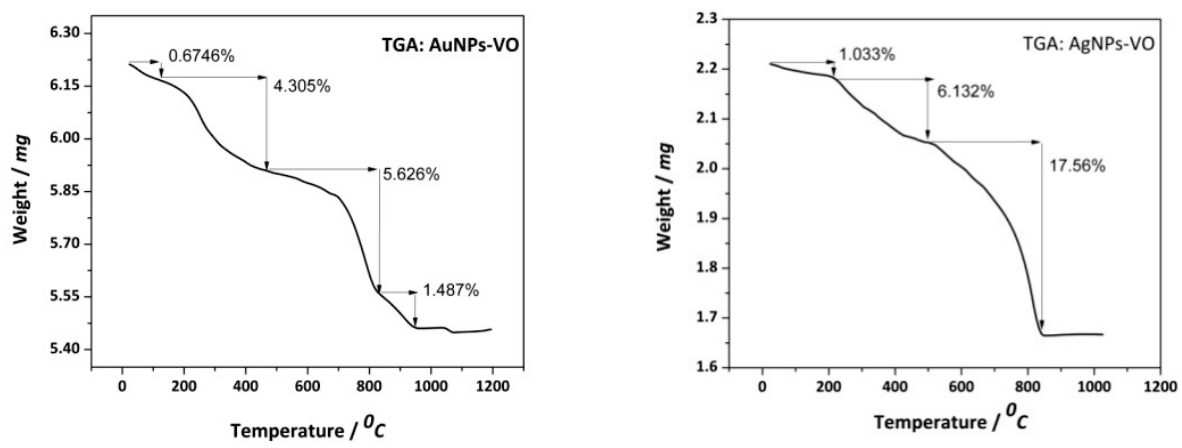

Figure 17. TGA profile for AuNPs-VO and AgNPs-VO 
TGA and DSC analysis of nanomaterials based on metallic nanoparticles are very commonly studied with respect to sintering nanoparticle inks for printed electronics [96-100]. Yu et al. [99] presented TGA results and DSC profiles of AgNPs-organic molecules (in their case, the silver nanoparticles were obtained using sodium polyacrylate and ascorbic acid) with sizes of 20-30, 30-40 and 100-120 nm. The DSC analyses showed some exothermic peaks in the temperature range of $200-280^{\circ} \mathrm{C}$. They concluded that these peaks were due to the surface sintering reaction of AgNPs or the recrystallization of nanoparticles by heating. For AgNPs $100 \mathrm{~nm}$ in size, there was no exothermic peak in the DSC curve, likely due to the fact that surface sintering is more difficult for larger AgNPs. At low temperatures, smaller AgNPs readily coalesce.

The research of Smith and Hutchinson [100] indicated the dependency of the sintering process on the size of the nanoparticle and ligand shell. TGA revealed that the free ligand decomposed at lower temperatures in comparison with the ligand bound to the nanoparticle. They showed that degradation is dependent on the composition rather than the size of the molecule. When the core size of nanoparticles was different but they bore the same ligand, it was found that larger nanoparticles lose ligands and sinterize more readily than smaller nanoparticles. This behavior suggests a greater stability of the ligand shell on smaller nanoparticles. Based on TGA and DSC analyses, they deduced that sintering is triggered by a very small amount of ligand loss. The sintering process is initiated and then the ligand is rapidly removed from the metallic surface and forms a porous film. This study showed that it is important to take into consideration both the nanoparticle core size and the ligand identity in the process of sinterization.

A DSC thermogram of free anthocyanin was presented by Santos et al. [3]. The decomposition of free anthocyanin took place in the range of $150-200^{\circ} \mathrm{C}$.

In our case, thermal effects on nanomaterials were measured by DSC under a nitrogen flow. The endothermic peak showed the decomposition of pure anthocyanin in the range of $210-240{ }^{\circ} \mathrm{C}$ [101]. The AuNPs-K presented an endothermic peak at $50{ }^{\circ} \mathrm{C}$, which represents water desorption, and an exothermic peak at $160-210^{\circ} \mathrm{C}$, which represents crystalline rearrangement by the sintering of metallic aggregates. For AgNPs-K, a small endothermic peak was seen at $160{ }^{\circ} \mathrm{C}$, representing some decomposition in organic molecules; after that, a peak at $170-210{ }^{\circ} \mathrm{C}$ representing crystalline rearrangement was found. This behavior suggests that, in the case of AuNPs-K, the lack of an organic molecule decomposition signal is due to the large particle diameter (Figure 18).

In the case of AuNPs-VO, there was a large exothermic peak at $300-400{ }^{\circ} \mathrm{C}$ and for AgNPs-VO at $280-450{ }^{\circ} \mathrm{C}$, both representing the recrystallization of nanoparticles by heating. 

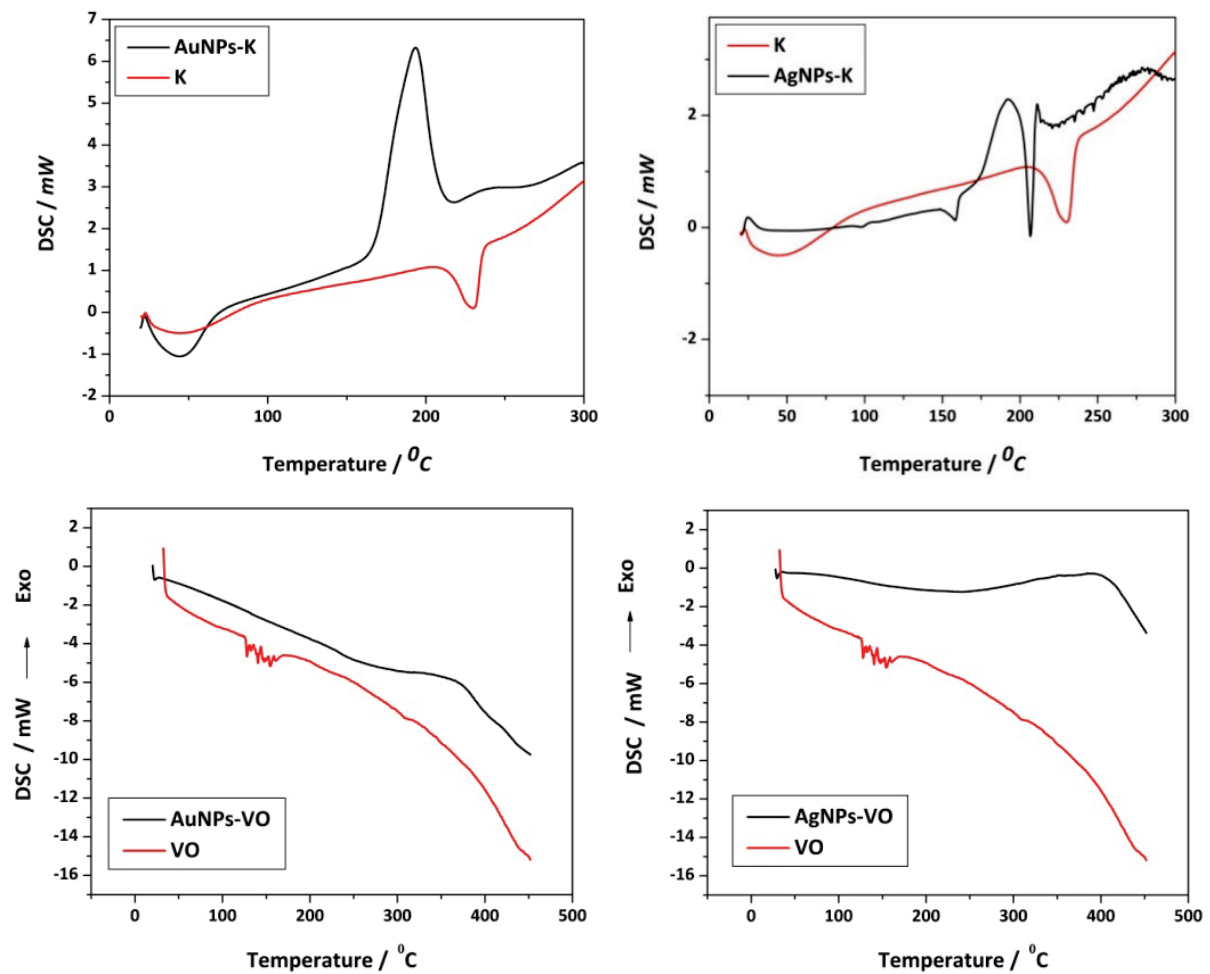

Figure 18. DSC curves for $K$, AuNPs-K, AgNPs-K, VO, AuNPs-VO and AgNPs-VO

We estimated by computation the number of ligand molecules coordinated onto the metallic nanoparticle as being 525 for gold and 355 in the case of silver (knowing the concentrations and the volumes of the solutions used in the synthesis).

A schematic representation of the formation of colloidal metallic nanoparticles is presented in Figure 19.<smiles>[R]C1=CC(O)C(=O)C=C1C</smiles><smiles>[R]c1ccc2c(c1)OC1Oc3ccc([R])cc3OC1(C)O2</smiles><smiles>Oc1cc(O)c2c(c1)OCC(O[Ga])=C2</smiles>

Figure 19. Schematic diagram for AuNPs / AgNPs-K formation 


\subsection{APPLICATION OF NANOMATERIALS ON PSORIATIC LESIONS}

The AuNPs / AgNPs-VO and AuNPs / AgNPs-K described above [102,103] were added to an emollient cream (patent in preparation).

The aim of this study was to assess changes to the skin induced by topical therapy based on VO / K conjugated with metal nanoparticles in patients with psoriasis. The research incorporated a clinical study, an ultrasound evaluation and statistical evaluations.

The clinical study was performed at Dermatology Clinic, Cluj-Napoca, Romania. All patients with a diagnosis of psoriasis vulgaris, confirmed by pathology, were aged between 35-63. The skin erythematous squamous plaques covered less than $15 \%$ of the body surface. The study was approved by the Ethical Committee of the University of Medicine and Pharmacy Iuliu Hatieganu Cluj-Napoca Romania. The picture in Figure 20 shows one of these cases.

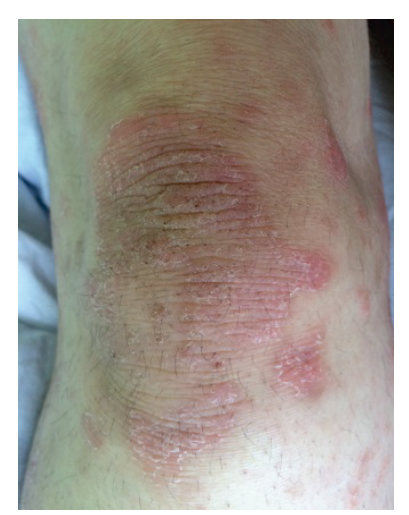

Figure 20. Psoriatic lesion - before treatment

In recent decades, high frequency ultrasonography using probes of at least $20 \mathrm{MHz}$ has been used in dermatology to non-invasively assess different skin lesions and the efficacy of therapy. Different published studies have shown that following different topical treatment for psoriasis plaques, there is a decrease in dermal thickness and a corresponding increase in dermal echo density. Consequently, a ultrasound evaluation was performed with a Dermascan C device (Cortex Technology, Denmark) at $20 \mathrm{MHz}$, which permits the in vivo acquisition of cross-sectional images of the skin up to $2 \mathrm{~cm}$ in depth. The device is made up of a transducer, an elaboration system and a data storage system. The ultrasonographic images were processed using specific software (Dermavision). The amplitudes of the echoes of the pixels are given as a value on a numerical scale that ranges from $0-255$. The low-echogenicity pixel area corresponds to the interval $0-30$, the high echogenicity pixels to the interval 
200-255 and the medium echogenicity pixels to 509-150. On a normal cutaneous image, the epidermal echogenicity appears as a white band, and the dermis is a combination of pixels of different amplitudes that may indicate different local processes. An increased number of low echogenicity pixels organized as a band or as diffuse localized process may indicate an inflammatory reaction or edema.

For every subject, we assessed the thickness of the epidermis and dermis in millimeters and the echogenicity variation by comparing the number of pixels with different amplitudes before and after therapy, at the same lesion.

For six weeks, patients underwent only topical treatment. They used creams with $2 \%$ AuNPs-VO or AgNPs-VO every day, and then creams with Au-K and Ag-K, for different lesions. Figure 21 shows the good effect of the creams on the same patient whose knee was shown in Figure 20.

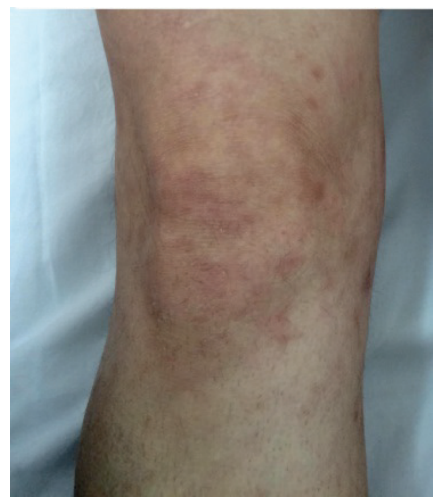

Figure 21. Psoriatic lesions - after treatment with AuNPs-VO cream

In order to determine the significance of the observed results, the ultrasonographic data were mathematically assessed.

Concerning the nanomaterials based on AuNPs-VO / AgNPs-VO, the anti-inflammatory effect was the best (compared with all other creams) in the case of the gold product (the mean value of skin thickness decreased from $3437.75 \mathrm{~mm}$ to $938 \mathrm{~mm}$ ). The good results were statistically significant according to a two-tailed Student's t-test, a good correlation was found in the data. The good correlation is between the thickness of skin and the antiinflamatory effect of the cream based on gold nanoparticles, in the sense that the thickness decreasness is perfectly correlated with the using of this cream. The $p$ value was 0.005 (level of significance) and the correlation coefficient $\mathrm{R}=87.4 \%$. Figure 22 also shows the good anti-inflammatory effect of AuNPs-VO. 

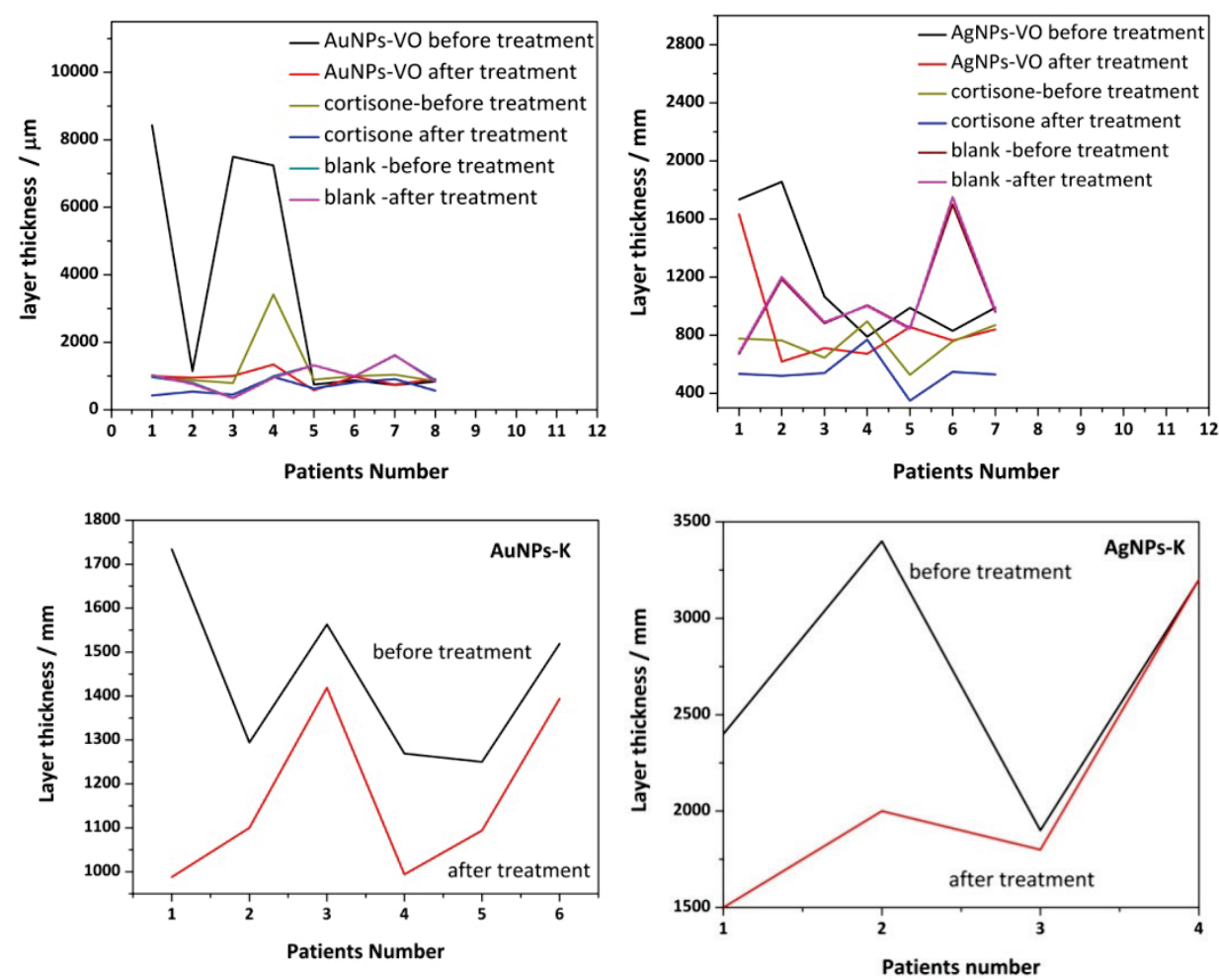

Figure 22. Anti-inflammatory effect of AuNPs-VO / AgNPs-VO after treatment

Concerning the nanomaterials AuNPs-K/AgNPs-K, good results were also found for the gold nanomaterial. The mean value of skin thickness decreased from 1438.1667 at $1164.8333 \mathrm{~mm}$. Unfortunately, the data did not correlate, so we cannot state that the result is statistically significant, and may have occurred due to chance.

\subsection{CONCLUSION}

Bio-nanomaterials based on gold / silver nanoparticles and anthocyanins from natural extracts, such as pure kuromanin chloride, were prepared using a green synthesis method. These nanomaterials were investigated from the morphological, structural and thermal point of view. The obtained nanomaterials were stable for 3 weeks, if kept at a temperature of $4{ }^{\circ} \mathrm{C}$. Due to their biocompatibility and stability, these nanomaterials were successfully used as a medical treatment. For this reason, gold and silver nanoparticles were added to emollient creams, which were used on psoriatic lesions in several groups of patients; remarkable improvements in disease conditions were observed. The best results were obtained using the AuNPs-VO nanomaterial. The use of creams based on new hybrid materials may be 
extended to other types of dermatoses that have topical therapy as the first indication.

\subsection{FUTURE WORK}

In the near future, we intend to prepare new gold / silver nanoparticles based on semisynthesis compounds with pure anthocyanin and tryptophan. These new nanoproducts will be introduced in creams for psoriatic lesions, taking into consideration that lower levels of epidermal tryptophan are involved in many types of skin disease.

\section{ACKNOWLEDGMENTS}

This work was performed with the framework project no 147 / 2012, through the program "Partnerships in priority areas-PN II", developed with the support of ANCS, CNDI-UEFISCDI, Romania.

Aspects of AuNPs-VO preparation, characterization and application were adapted from the paper: New nanomaterials for the improvement of psoriatic lesions, published in the Journal of Materials Chemistry [63], by permission of The Royal Society of Chemistry (RSC).

Aspects of AuNPs / AgNPs-VO optimization procedure were adapted from the paper: Effect of natural extract $p H$ on morphological characteristics of hybrid materials based on gold nanoparticles, published in AIP Conference Proceedings [73], by permission of AIP Publishing.

Aspects of AuNPs / AgNPs-K preparation, characterization and application have not been published before. 


\section{REFERENCES}

1. Arcadia Blog, http://www.arcadiamedical.ro/blog/2014/09/psoriazisul-oprivire-moderna-asupra-unei-afectiuni-vechi/ (accessed on March 18, 2015).

2. R.V. Filimon, D. Beceanu, M. Niculaua, C. Arion. Agronom. Res. Mold. 44 (2011) 81-91.

3. D.T. Santos, J.Q. Albarelli, M.M. Beppu, M.A.A. Meireles. Food Res. Int. 50 (2013) 617-624.

4. T. Tsuda, F. Horio, K. Uchida, H. Aoki, T. Osawa. J. Nutr. 133 (2003) 2125-2130.

5. I.T. Nizamutdinova, Y.M. Kim, J. Chung, S.C. Shin, Y.K. Jeong, H.G. Seo, J.H. Lee, K.C. Chang, H.J. Kim. Food Chem. Toxicol. 47 (2009) 2806-2812.

6. W.L. Barnes, A. Dereux, T.W. Ebbesen. Nature 424 (2003) 824-830.

7. G. Raschke, S. Kowarik, T. Franzl, C. Sonnichsen, T.A. Klar, J. Feldmann. Nano Lett. 3 (2003) 935-938.

8. C.F. Bohren, D.R. Huffmann. Absorption and scattering of light by small particles; John Wiley \& Sons: New York, USA 1983, 1-544.

9. H.H. Lara, N.V. Ayala-Nunez, L. Ixtepan-Turrent, C. Rodriguez-Padilla. J. Nanobiotechnol. 8 (2010) 1-10.

10. J.D. Trono, K. Mizuno, N. Yusa, T. Matsukawa, K. Yokoyama, M. Uesakaj. Radiat. Res. 52 (2011) 103-109.

11. R. Sinha, G.J. Kim, S. Nie, D.M. Shin. Mol. Cancer Ther. 5 (2006) 1909-1917.

12. Y. Wang, X. Xie, X. Wang, G. Ku, K.L. Gill, D.P. O’Neal, G. Stoica, L.V. Wang. Nano Lett. 4 (2004) 1689-1692.

13. M. Auffan, J. Rose, M.R. Wiesner, J.-Y. Bottero. Environ. Pollut. 157 (2009) 1127-1133.

14. C.N.R. Rao, G.U. Kulkarni, P.J. Thomas, P.P. Edwards. Chem. Soc. Rev. 29 (2000) 27-35.

15. F. Mafune, J.-Y. Kohno, Y. Takeda, T. Kondow. J. Phys. Chem. B 106 (2002) 7575-7577.

16. K.N. Thakkar, S.S. Mhatre, R.Y. Parikh. Nanom. Nanotech. Biol. Med. 6 (2010) 257-262.

17. N. Kulkarni, U. Muddapur. J. Nanotechnol. 2014 (2014) 1-8.

18. S. Prabhu, E.K Poulose. Int. Nano Lett. 2 (2012) 32-42.

19. A. Chauhan, S. Zubair, S. Tufail, A. Sherwani, M. Sajid, S.C. Raman, A. Azam, M. Owais. Int. J. Nanomedicine 6 (2011) 2305-2319.

20. N. Pantidos, L.E Horsfall. J. Nanomed. Nanotechnol. 5 (2014) 1-10.

21. S.S. Shankar, A. Ahmad, R. Pasricha, M. Sastry. J. Mater. Chem. 13 (2003) 1822-1826.

22. M. Ahamed, M.S. AlSalhi, M.K.J. Siddiqui. Clin. Chim. Acta 411 (2010) 1841-1848.

23. L. Ge, Q. Li, M. Wang, J. Ouyang, X. Li, M.M.Q. Xing. Int. J. Nanomedicine 9 (2014) 2399-2407.

24. B. Fadeel, A.E. Garcia-Bennett. Adv. Drug Deliv. Rev. 62 (2010) 362-374.

25. J.Y. Song, H.-K. Jang, B.S. Kim. Process Biochem. 44 (2009) 1133-1138.

26. B. Baishya, M.C. Kalita. Int. J. Pharm. Bio. Sci. 4 (2013) 873-881.

27. D.D. Lekeufack, A. Brioude. Dalton Trans. 41 (2012) 1461-1464.

28. N. Ahmad, S. Sharma. Int. J. Nanopart. 5 (2012) 185-195.

29. I.T. Muralikrishna, M. Pattanayak, P.L. Nayak. J. Nano Sci. Technol. 3 (2014) 45-51. 
30. P. Elia, Z. Rach, S. Hazan, S. Kolusheva, Z. Porat, Y. Zeiri. Int. J. Nanomedicine 9 (2014) 4007-4021.

31. N. Chanda, R. Shukla, A. Zambre, S. Mekapothula, R.R. Kulkarni, K. Katti, K. Bhattacharyya, G.M. Fent, S.W. Casteel, E.J. Boote, J.A. Viator, A. Upendran, R. Kannan, K.V. Katti. Pharm. Res. 28 (2011) 279-291.

32. J. Pulit, M. Banach. Dig. J. Nanomater. Bios. 8 (2013) 1295 - 1300.

33. E. Rodriguez-Leon, R. Iniguez-Palomares, R.E. Navarro, R. Herrera-Urbina, J. Tanori, C. Iniguez-Palomares, A. Maldonado. Nanoscale Res. Lett. 8 (2013) $1-9$.

34. P. Logeswari, S. Silambarasan, J. Abraham. J. Saudi Chem. Soc. 19 (2012) 311317.

35. P. Logeswari, S. Silambarasan, J. Abraham. Sci. Iran. 20 (2013) 1049-1054.

36. A.M. Abdelmonema, R.M. Amin. Int. J. Sci. Basic Appl. Res. 15 (2014) 57-65.

37. D. Mubarak Ali, N. Thajuddin, K. Jeganathan, M. Gunasekaran. Colloids Surf. B Biointerfaces 85 (2011) 360-365.

38. J. Kasthuri, S. Veerapandian, N. Rajendiran. Colloids Surf. B Biointerfaces 6 (2009) 55-60.

39. S.K. Sivaraman, I. Elango, S. Kumar, V. Santhanam. Curr. Sci. 97 (2009) 1055-1059.

40. N. Ahmad, S. Sharma. GSC 2 (2012) 141-147

41. S.S. La, P.L. Nayak. IJSID 2 (2012) 325-350.

42. R.S. Varma, B. Baruwati, G.E. Hoag, J.B. Collins, US Patent US 2011/0110723.

43. H. Devnani, S.P. Satsangee. Int. J. Environ.Sci.Technol. 12 (2015) 1269-1282.

44. S. Kalmodia, J. Harjwani, R. Rajeswari, W. Yang, C.J. Barrow, S. Ramaprabhu, S. Krishnakumar, S.V. Elchuri. Int. J. Nanomedicine 8 (2013) 4327-4338.

45. P.N. Chen, C.S.C. Hu, C.H.L. Hiou, W.H. Kuo, C.L. Chiang. Cancer Lett. 235 (2006) 248-259.

46. M.J. Awika, W.L. Rooney, D.R. Waniska. Food Chem. 90 (2004) 293-301.

47. F. Mattivi, R. Guzzon, U. Vrhovsek, M. Stefanini, R. Velasco. J. Agric. Food Chem. 54 (2006) 7692-7702.

48. B. Jayaprakasam, S.K. Vareed, L.K. Olson, M.G. Nair. J. Agric. Food Chem. 53 (2005) 28-31.

49. S.Y. Kang, N.P. Seeram, M.G. Nair, L.D. Bourquin. Cancer Lett. 194 (2003) 13-19.

50. H. Wang, M.G. Nair, G.M. Strasburg, Y.C. Chang, A.M. Booren, I.J. Gray, D.L. DeWitt. J. Nat. Prod. 62 (1999) 294-296.

51. T. Tsuda, F. Horio, K. Uchida, H. Aoki, T. Osawa. J. Nutr. 133 (2003) 2125-2130.

52. R.M. Kershi, N. Ebrahim. Int. J. Mater. Biomater. Appl. 4 (2014) 14-18.

53. V.K. Ivanov, A.V. Usatenko, A.B. Shcherbakov. Russ. J. Inorg. Chem. 54 (2009) $1522-1527$.

54. J. Chen, X. Tao, M. Zhang, A. Sun, L. Zhao. J. Sci. Food Agr. 94 (2014) 1781-1786.

55. P.L. Nadworny, J. Wang, E.E. Tredget, R.E. Burrell. J. Inflmm. (Lond) 7 (2010) $1-20$.

56. Y. He, Z. Du, H. Lv, Q. Jia, Z. Tang, X. Zheng, K. Zhang, F. Zhao. Int. J. Nanomedicine 8 (2013) 1809-1815.

57. J. Jain, S. Arora, J.M. Rajwade, P. Omray, S. Khandelwal, K.M. Paknikar. Mol. Pharm. 6 (2009) 1388-1401.

58. I.I. Stepniak, M.J. Santos-Martinez, C. Medina, M.W. Radomski. Int. J. Nanomedicine 9 (2014) 1677-1687. 
59. F.K. Santos, M.H. Oyafuso, C.P. Kiill, G.M.P.D. Remiao, M. Chorilli. Curr. Nanosci. 9 (2013) 159-167.

60. C. Polinicencu, H. Popescu, C. Nistor. Clujul Medical 53 (1980) 160-163.

61. H. Chang, M.-J. Kao, T.-L. Chen, H.-G. Kuo,K.-C. Choand, X.-P. Lin. Am. J. Eng. Appl. Sci. 4 (2011) 214-222.

62. M. Alhamed, A.S. Issa, A. Wael Doubal. J. Electron Dev. 16 (2012) 1370-1383.

63. M. Crisan, L. David, B. Moldovan, A. Vulcu, S. Dreve, M. Perde-Schrepler, C. Tatomir, A.G. Filip, P. Bolfa, M. Achim, I. Chiorean, I. Kacso, C. Berghian Grosan, L. Olenic. J. Mater. Chem. B 1 (2013) 3152-3158.

64. A. Filip, D. Daicoviciu, P. Bolfa, S. Clichici, A. Muresan, L. David, L. Olenic, IUPS, Birmingham, UK, July 21-26, 2013, Abstract No. PCB 149.

65. A. Filip, S. Clichici, P. Bolfa, A. Muresan, I. Baldea, D. Olteanu, L. David, L. Olenic, XII International Conference on Nanostructured Materials (NANO 2014) Moscow, Russia July 13-18 2014, p. 802.

66. A. Filip, S. Clichici, L. David, L. Olenic, P. Bolfa, G. Borza, D. Olteanu, I. Baldea, M. Achim, A. Muresan, XXVII th National Conference on Physiology of the Romanian Society of Physiology, Romania 5-7 June 2014, p. 9.

67. M. Perde-Schrepler, E. Fischer-Fodor, P. Virag, O. Soritau, I. Brie, C. Tatomir, F. Imre-Lucaci, A. Florea, L. David, L. Olenic, The VIth International Conference on oxidativ stress in Dermatology and Biology, Andros, Greece, 28-31 August 2014, p. 113.

68. M. Perde-Schrepler, E. Fischer-Fodor, P. Virag, O. Soritau, I. Brie, L. David, L. Olenic, OECI 2014 Oncology Days, Cluj-Napoca, Romania, 13-14 June 2014, p. 63.

69. B. Moldovan, O. Ghic, L. David, C. Chisbora. Rev. Chim. Bucharest 63 (2012) 463-464.

70. M.M. Giusti, L.E. Rodriguez-Saona, R.E. Wrolstad. J. Agric. Food Chem. 47 (1999) 4631-4635.

71. M.M. Giusti, R.E. Wrolstad, in Current Protocols in Food Analytical Chemistry, New York: John Wiley \& Sons, 2001, p. 1.

72. L. Olenic, A. Vulcu, I. Chiorean, M. Crisan, C. Berghian-Grosan, S. Dreve, L. David, L.B. Tudoran, I. Kacso, I. Bratu, C. Neamtu, C. Voica. AIP Conf. Proc. 1565 (2013) 238-242.

73. G.H. Woehrle, J.E. Hutchinson, S. Ozkar, R.G. Finke. Turk. J. Chem. 30 (2006) 1-13.

74. D.B. Williams, C.B. Carter, Transmission Electron Microscopy A Textbook for Materials Science, Springer, New York, USA, 2009, p. 5.

75. S.K. Ghosh, T. Pal. Chem. Rev. 107 (2007) 4797-4862.

76. M.M. Alvarez, J.T. Khouri, T.G. Schaaff, M.N. Shafigullin, I. Vezmar, R.L. Whetten. J. Phys. Chem. B 101 (1997) 3706-3712.

77. X. Huang, M.A. El-Sayed. J. Adv. Res. 1 (2010) 13-28.

78. S.P. Dubey, M. Lahtinen, M. Sillanpaa. Process. Biochem. 45 (2010) 1065-1071.

79. D.S. Sheny, J. Mathew, D. Philip. Spectrochim. Acta A 79 (2011) 254-262.

80. D.M. Smilgies. J. Appl. Crystallogr. 42 (2009) 1030-1034.

81. N. Ahmad, S. Sharma, V.N. Singh, S.F. Shamsi, A. Fatma, B.R. Mehta. Biotechnol. Res. Int. 2011 (2011) 1-8.

82. E.J. Espinosa-Ortiz, M. Vaca-Mier, in Nanotechnology for Water and Wastewater Treatment, P. Lens, J. Virkutyte, V. Jegatheesan, S.-H. Kim, S-Al Abed (Eds.), IWA Publishing, London, UK, 2013, p. 113. 
83. C.S.S.R. Kumar, Raman Spectroscopy for Nanomaterials Characterization, Springer-Verlag, Berlin Heidelberg, Ger, 2012, p. 1.

84. B. Zhang, B. Yan. Anal. Bioanal. Chem. 396 (2010) 973-982.

85. J.E. Herrera, N. Sakulchaicharoen, in Drug Delivery Nanoparticles Formulation and Characterization, Y. Pathak, D.Thassu (Eds.), Informa Healthcare USA, Inc, New York, USA, 2009, p. 239.

86. J.C. Merlin, J.P. Cornard. Spectrochim. Acta 50A (1994) 703-712.

87. N.B. Colthup, L.H. Daly, S.E. Wiberley, Introduction to Infrared and Raman Spectroscopy, Academic Press Inc., San Diego, USA, 1990, p. 1.

88. G. Socrates, Infrared and Raman Characteristic Group Frequencies Tables and Charts, John Wiley and Sons Ltd., Chichester, England, 2001, p. 1.

89. M. Hineno. Carbohydr. Res. 56 (1977) 219-227.

90. S. Tozzi, N. Zanna, P. Taddei. Food Chem. 141 (2013) 3586-3597.

91. A. Piccolo, F.J. Stevenson. Geoderma 27 (1982) 195-208.

92. Y.S. Velioglu, L. Ekici, E.S. Poyrazoglu. Int. J. Food Sci. Technol. 41 (2006) 1011-1015.

93. Spectral Database for Organic Compounds SDBS, http://sdbs.db.aist.go.jp/sdbs/cgi-bin/direct frame top.cgi (accessed on April 2015).

94. D. Wang, Y. Ma, C. Zhang, X. Zhao. LWT - Food Sci. Technol. 55 (2014) 645-649.

95. S. Aryal, B.K.C. Remant, N. Dharmaraj, N. Bhattarai, C.H. Kim, H.Y. Kim. J. Coll. Interf. Sci. 299 (2006) 191-197.

96. J. Sopousek, J. Bursik, J. Zalesak, Z. Pesina. J. Min. Metall. Sect. B-Metall. 48 (2012) 63-71.

97. Z. Yang, Nanoparticle Inks for Printed Electronics www.nanomastech.com (accessed on April 2015)

98. C.M.J. Coutts, M.B. Cortie, M.J. Ford, A.M. McDonagh. J. Phys. Chem. C 113 (2009) 1325-1328.

99. H. Yu, L. Li, Y. Zhang. Scripta Materialia 66 (2012) 931-934.

100. B.L. Smith, J.E. Hutchison. J. Phys. Chem. C 117 (2013) 25127-25137.

101. L. Olenic, I. Chiorean, M. Crisan, A. Vulcu, C. Grosan, L.B. Tudoran, I. Kacso, L. Magerusan, I. Bratu, ATOM N $20147^{\text {th }}$ Edition, 21-24 August 2014, Constanta, Romania, p. 1.

102. L. Olenic, A. Vulcu, A.C. Grosan, S. Dreve, (Romania), Patent no. A/00805 (submitted to OSIM in 2013)

103. L. Olenic, A. Vulcu, A.C. Grosan, S. Dreve, (Romania), Patent no. A/00263 (submitted to OSIM in 2014). 